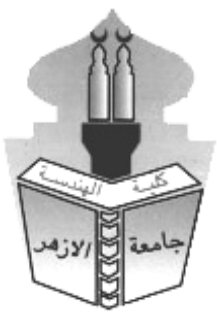

\title{
THE LINE OF ORGANIZATION AND ITS INFLUENCE ON URBAN HERITAGE AREAS
}

\author{
Haby Hosney Mostafa Ahmed \\ Architecture Department, Faculty of Fine Arts in Cairo, Helwan University, Cairo, \\ Egypt \\ E-mail: habyhosney@gmail.com
}

\begin{abstract}
The line of organization is one of the mechanisms of adjusting Architecture and Urban process, separating the public and private property and regulating the relationship between the building and the road. The organization line also represents the tool of expansion and planning of roads, fences and alleys, and often reflect the development of transport and movement at the city level and its revival in terms of the requirements for expansion and opening of roads in proportion to the type and size of these means.

The first written legislation issued to regulate the construction and planning of cities in 1878 under the name of "Constitution of the Organization relevance" stipulated the need to reform and organize the roadside in most cities Control the prominence and determine the width and the development of lines of regulation of the buildings.

The organization line is also an effective tool in many cases. It represents a serious danger to the fabric of the heritage areas of value that have extended their value from the formation of the fabric throughout the ages. In light to Architecture and Urbanism, for example, an important cultural heritage has stabilized the visual image and its moral and material value. Many of which are concept-based. The sites have become a tourist attraction at the national level and may have reached the global level, including those that may be recorded in World Heritage sites. These sites are listed by the World Heritage Committee as part of the World Heritage Site program Organized by UNESCO. In 1979, the historic Cairo area was registered on the World Heritage Register. The year 2011 witnessed the beginning of the adoption of heritage areas and the requirements of dealing with them at the local level.
\end{abstract}

KEYWORDS: Organization Line - Heritage areas - Urban Fabric -Heritage Character - Identity

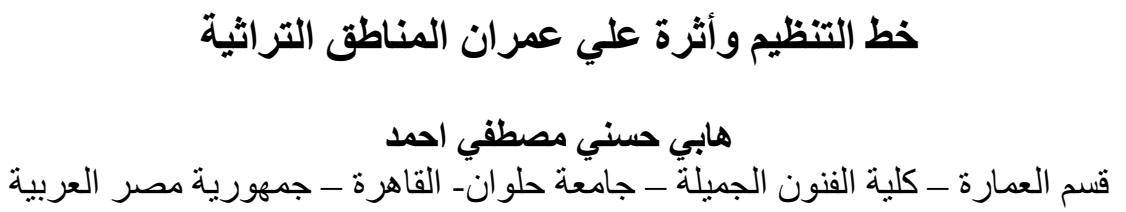

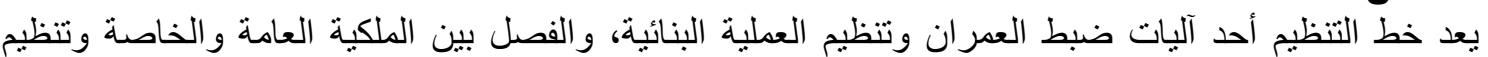

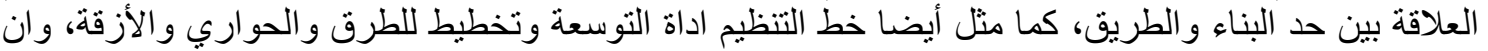
مثل في العديد من الأحيان انعكاس تطور وسائل النقل والانتقال علي مستوي المدينة وإحيائها متمثلا في منطلبات التيات

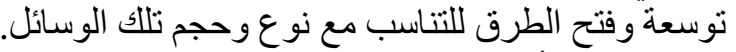

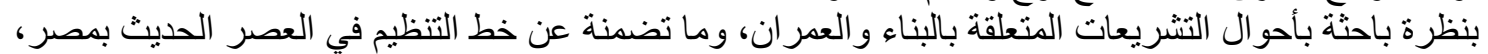

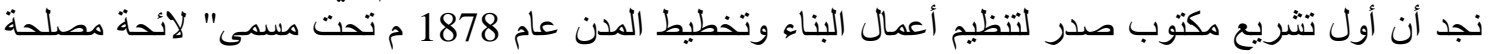


التنظيم" نصت اللائحة على ضرورة نهذيب وتتظيم حدي الطريق فى معظم المدن و التحكم في البروزات وتحديد عروضها ووضع خطوط تنظيم التئ للمباني.

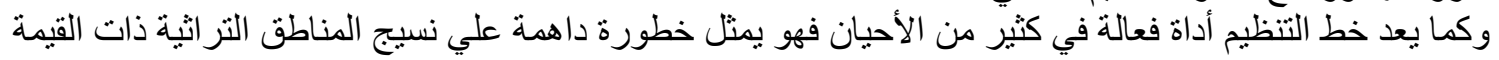

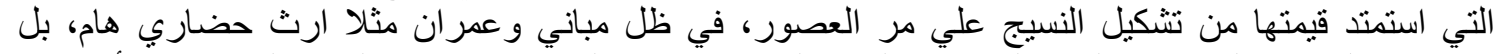

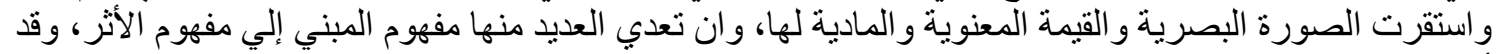

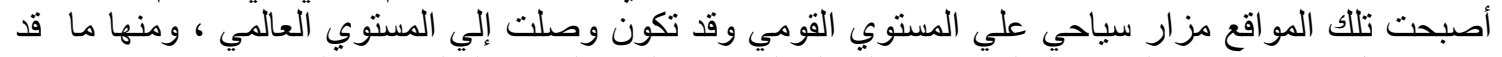

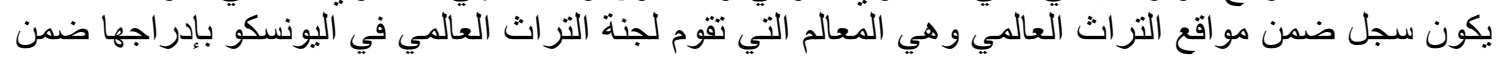

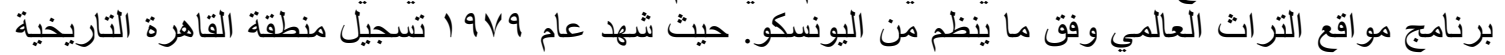

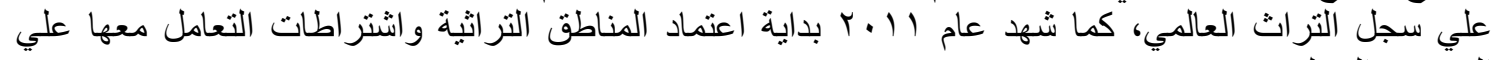

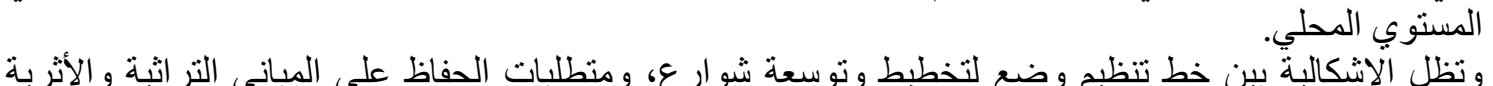

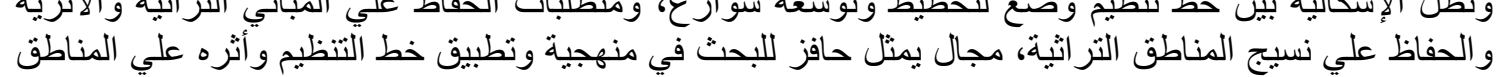

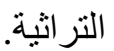
الكلمات المفتاحية: خط التنظيم ـ المناطق التراثية ـ النسيج العمراني ـ التراث ـ الطابع ـ الهوية.

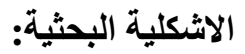

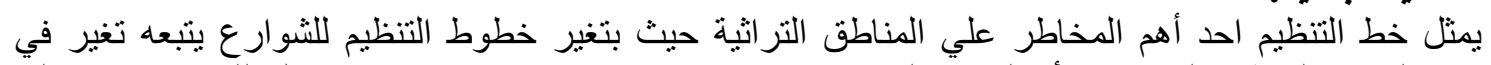

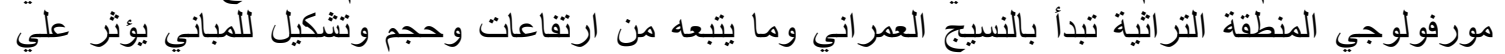

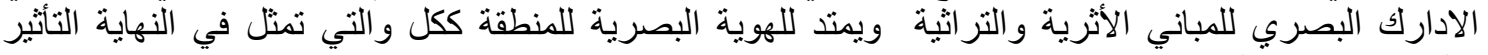
و التغير في طابع المناطق.

هل آلية وضئ البحئي إقرار خط التنظيم تتناسب مع منطلبات الحفاظ علي التراث المادي، والنسيج، للمناطق التراثية.

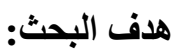
بحث اثر وآلية وضع و إقرار خط التنظيم ومدي تعارضه مع الأهداف الإستر اتيجية للحفاظ علي المناطق التراثية، وفق التشريعات الوطنية و المو اثيق الدولية المعنية بذلك الثنأن.

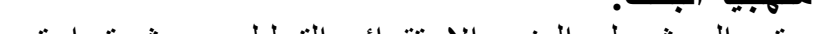

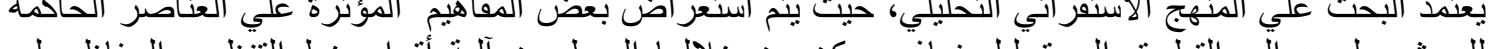

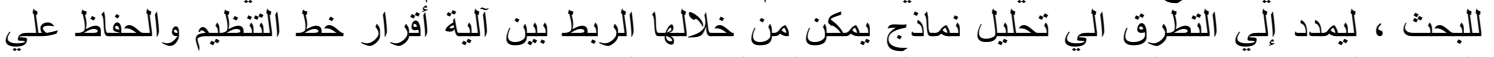
المناطق التر اثية، بهدف التحقق من اثر خط التنظيم علي المناطق التراثية التئ.

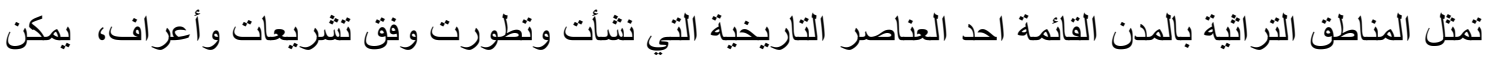

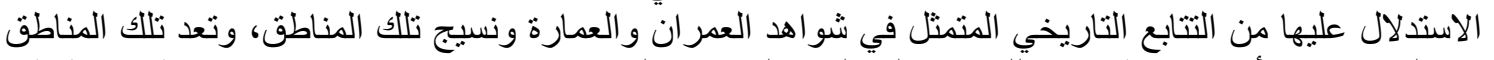

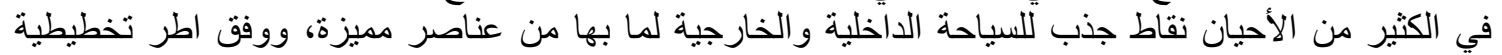

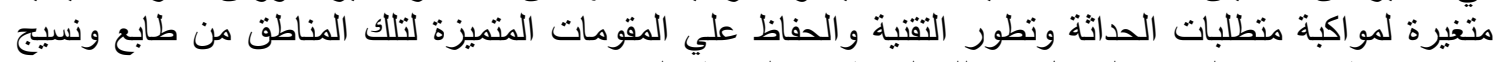

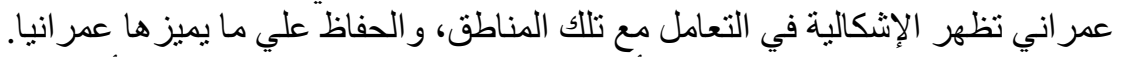

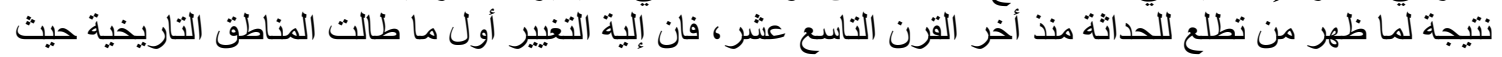

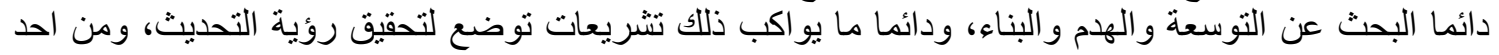

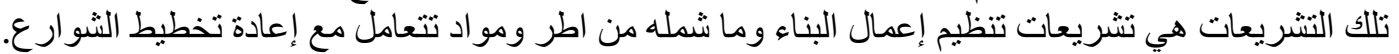

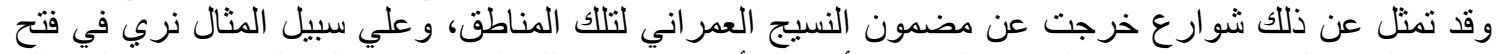

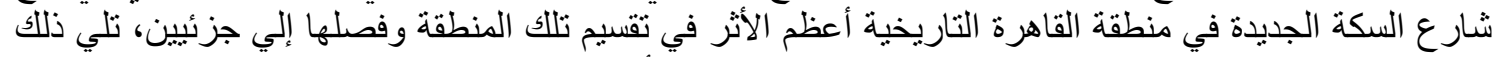

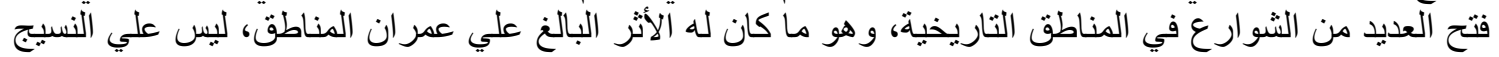

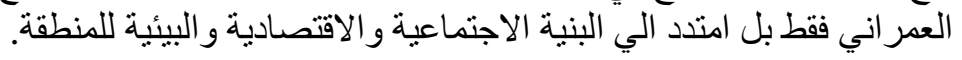



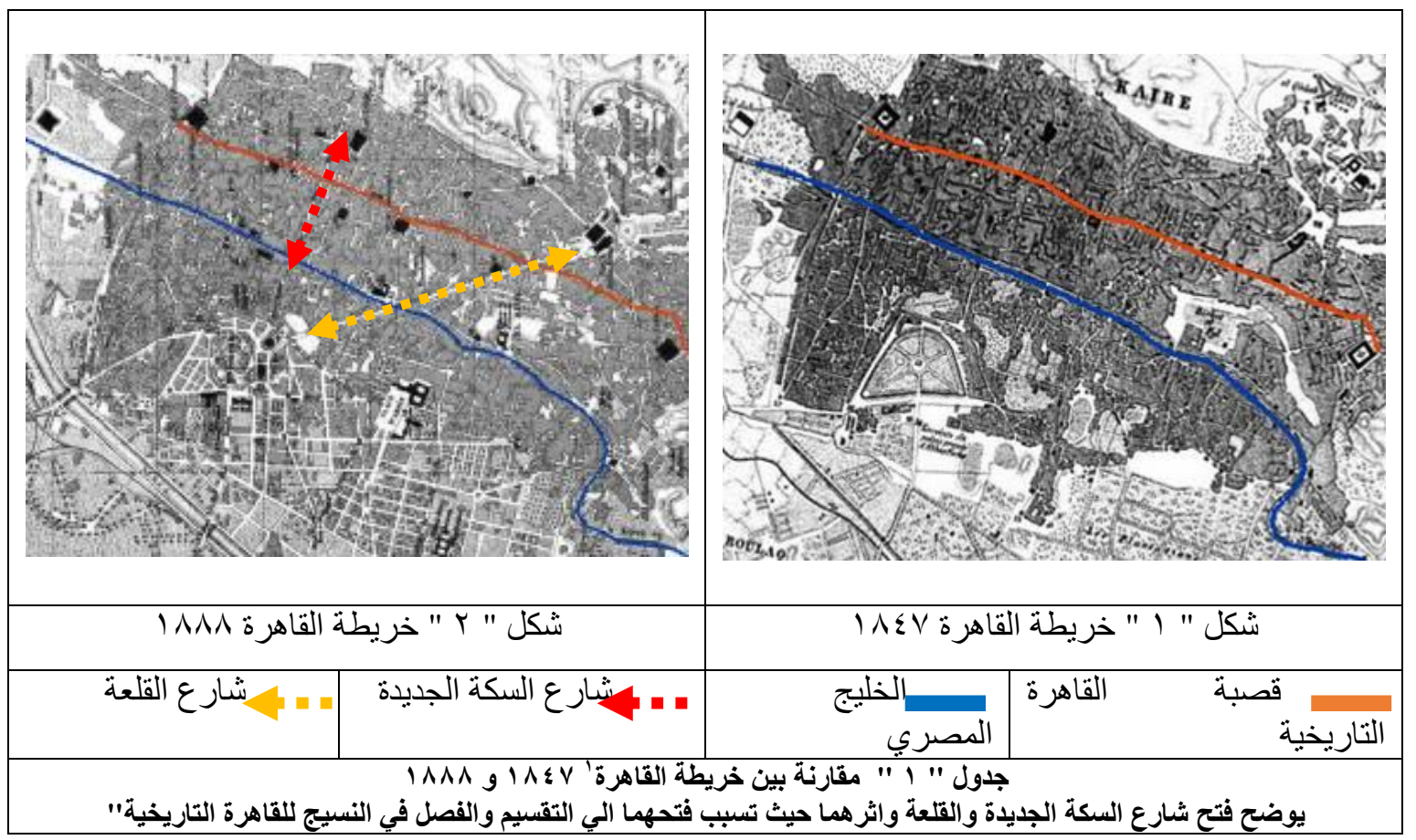

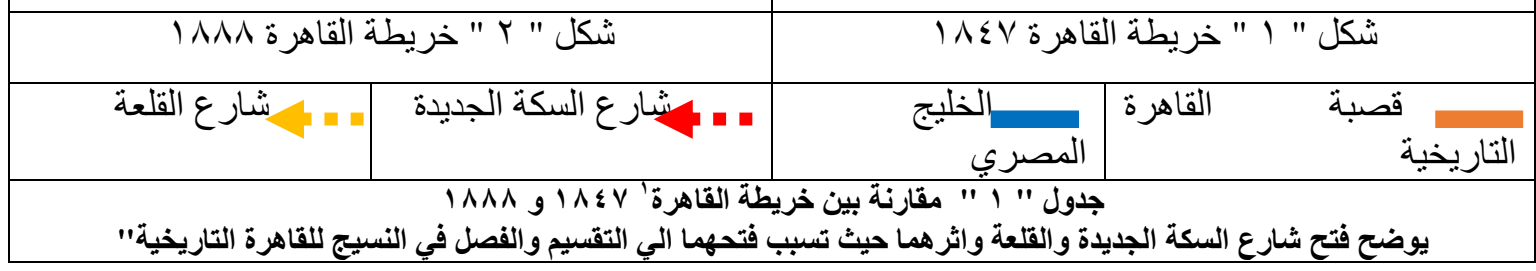

ا

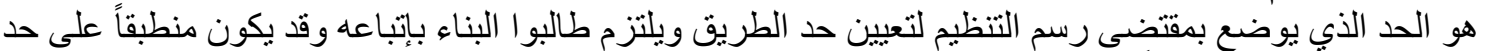

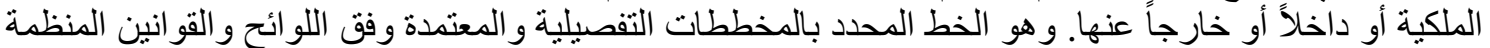

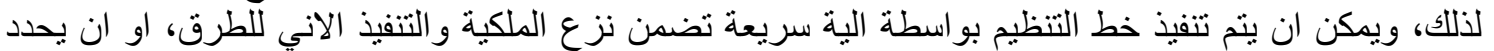

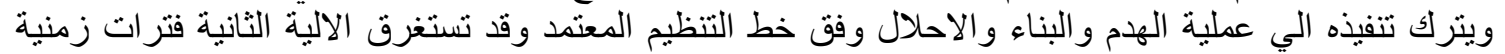

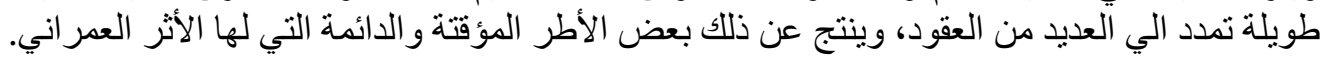

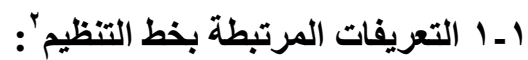

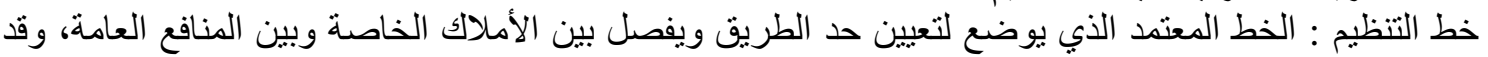

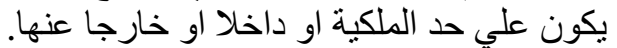

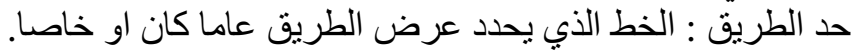
زو ائد التنظيم: المساحة الز ائدة المحصورة بين خط التنظيم وحد الملكية والناتجة عن وجود خط التنظيم خارج حدود الملكية. ضوائع التظيم : المساحة الواقعة بين خط التنظيم وحد الملكية والناتجة عن وجود خط تنظيم داخل حدود الملكية

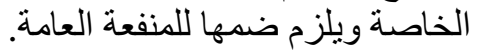

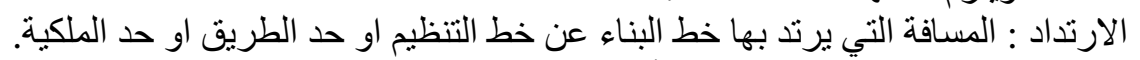

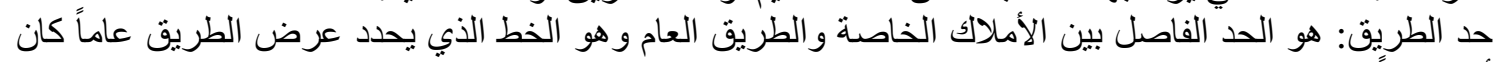
أو خاصاً.

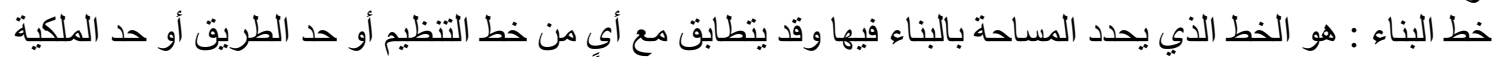

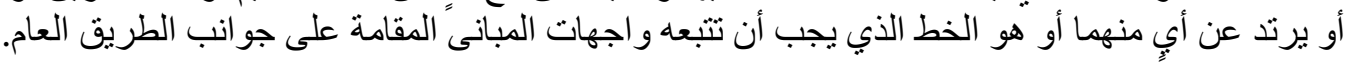

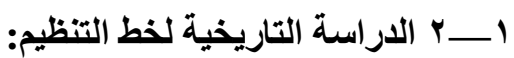

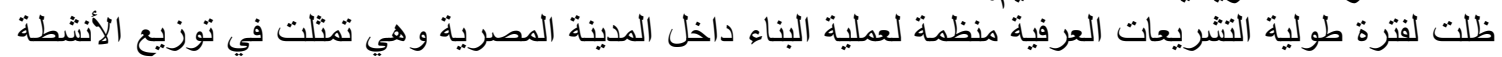

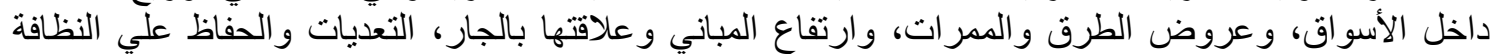

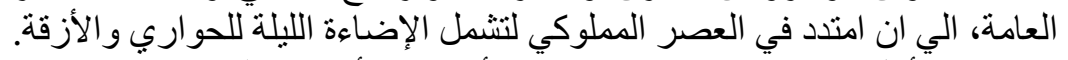

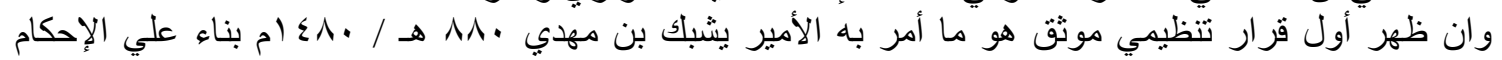

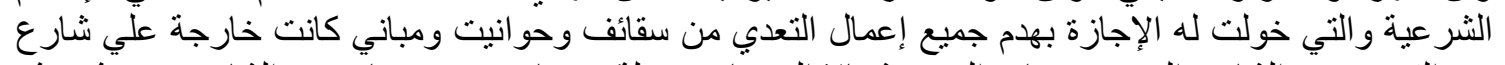

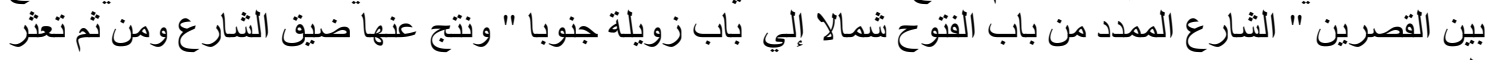
المرور فيه. 
ولقد فرضت دولة المماليك نظم إدارية تتسم بالثدة و الصر امة و المر اقبة الثديدة لشوارع القارعة القاهرة القديمة وحار اتها

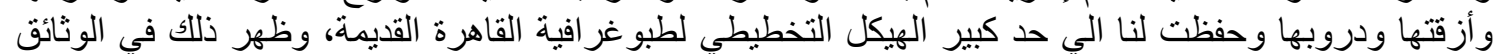

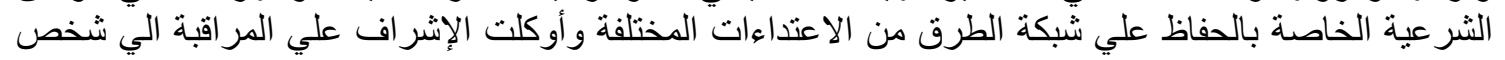

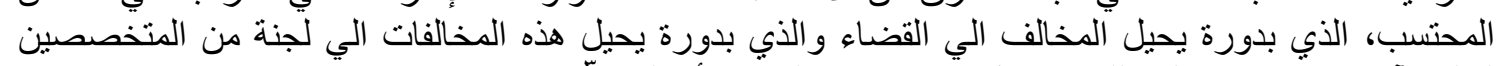

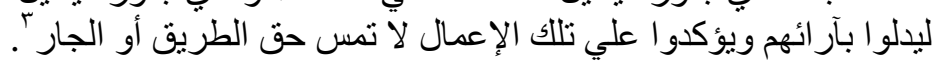

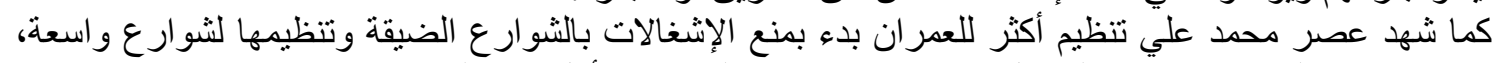

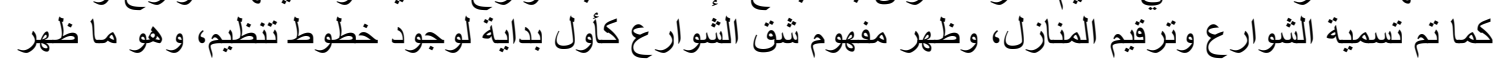

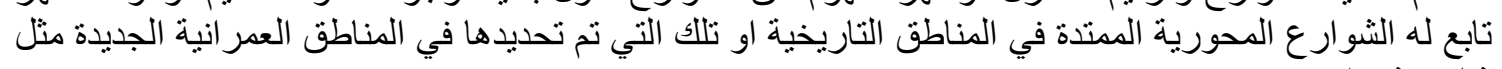

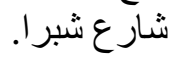

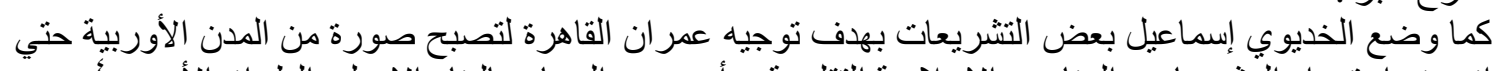

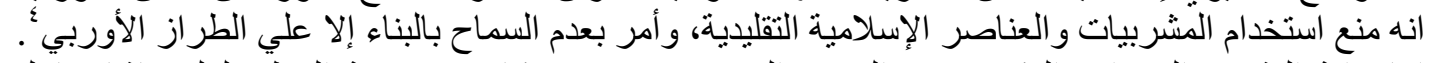

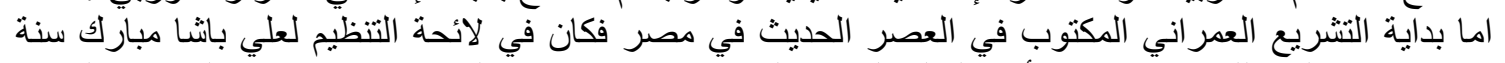

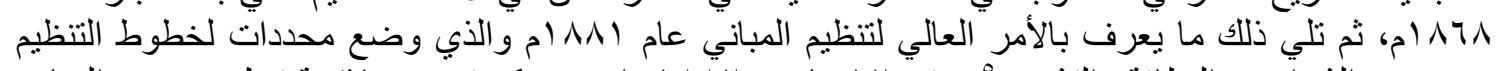

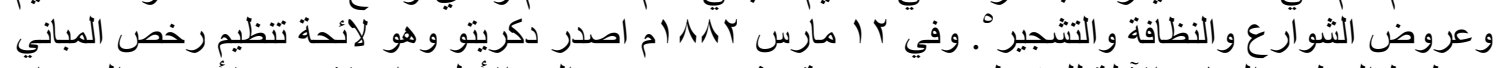

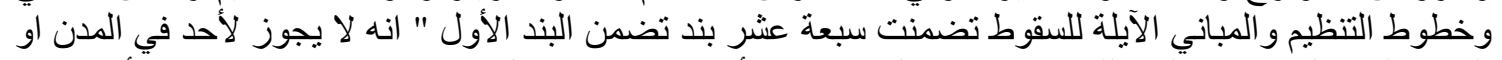

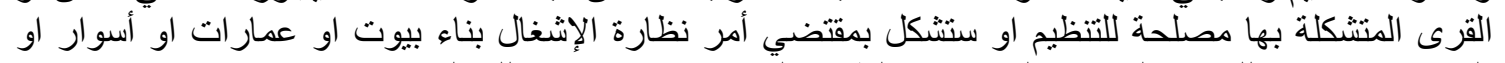

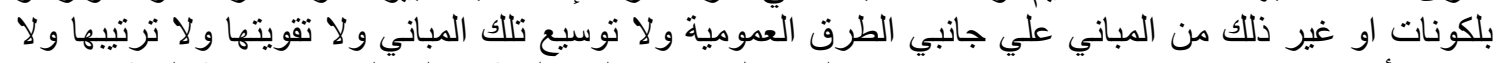

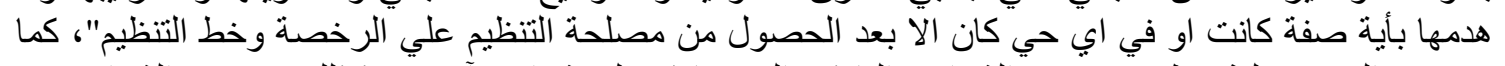

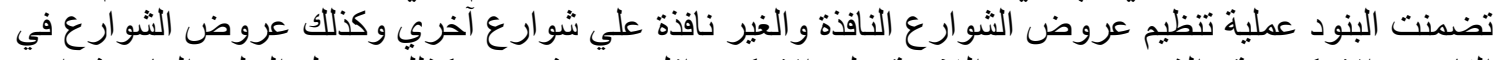

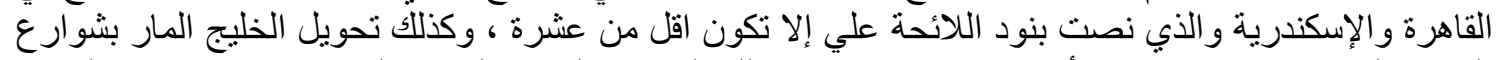

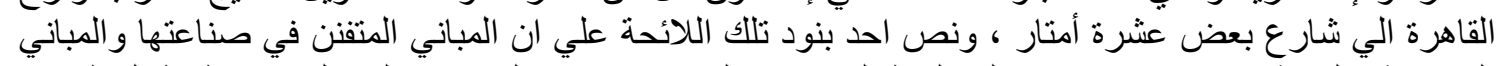

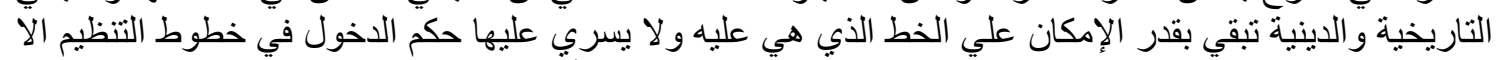

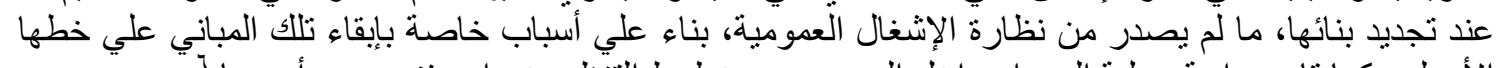

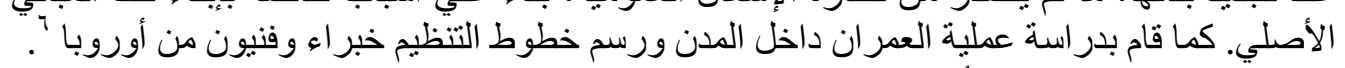

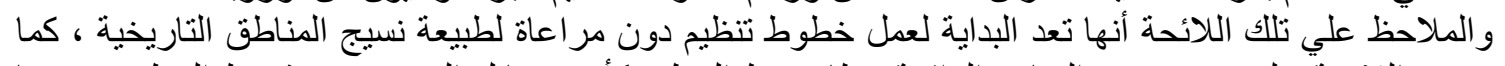

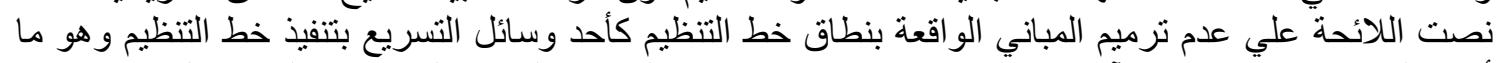

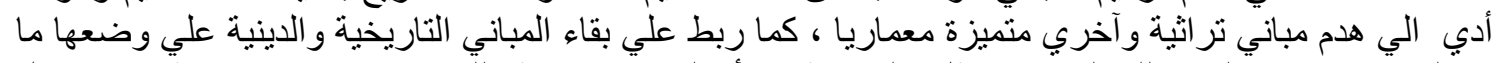

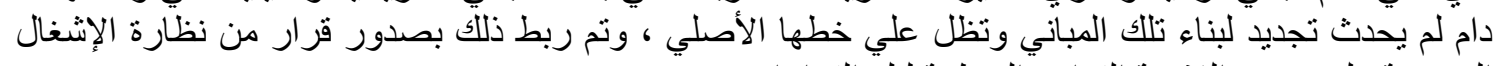

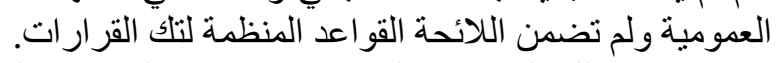

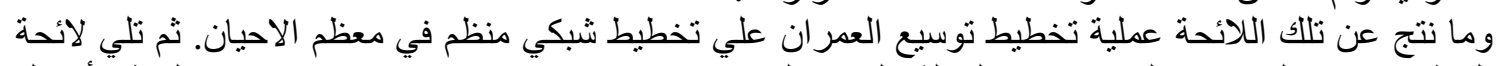

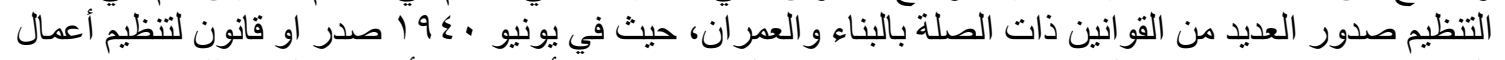

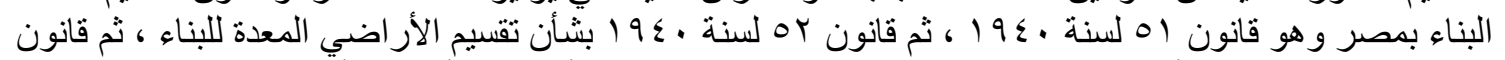

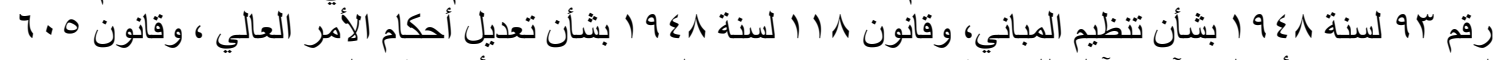

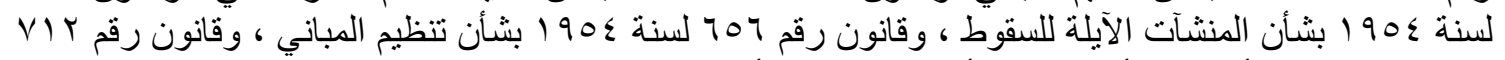

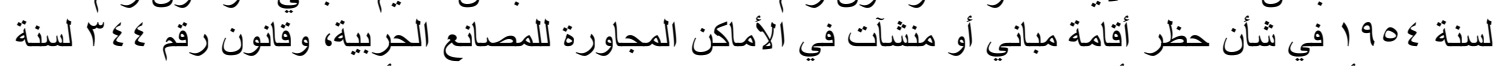

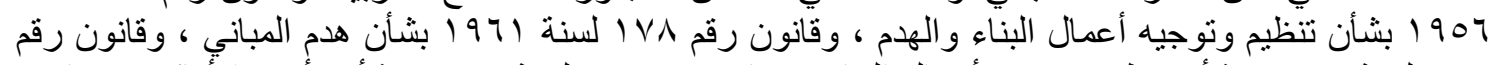

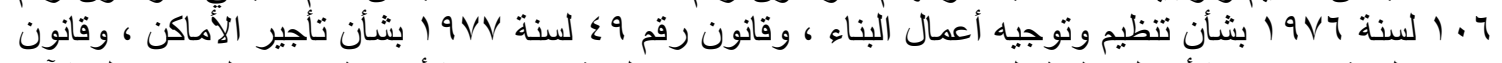

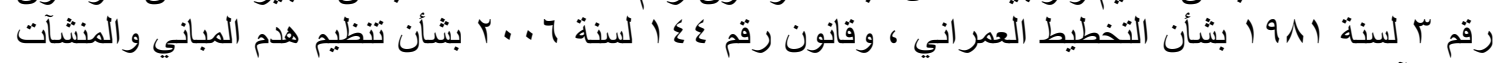

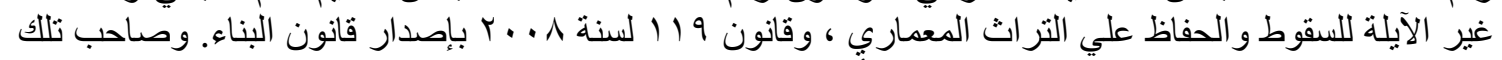
القو انين العديد من القرارات التنفيذية والتي من شأنها التعديل ببعض التعض من مو اد تلك القانو نين.

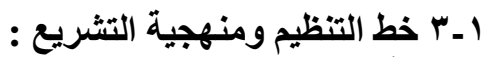

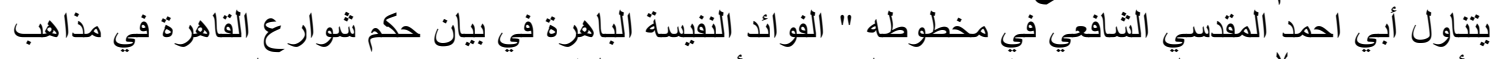

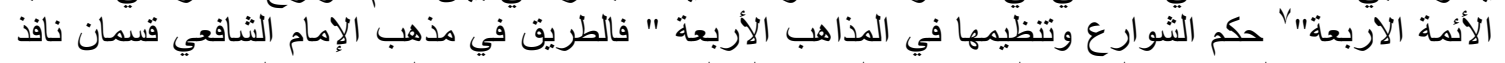

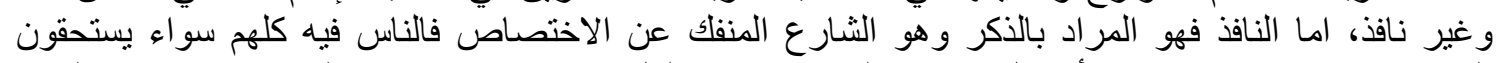

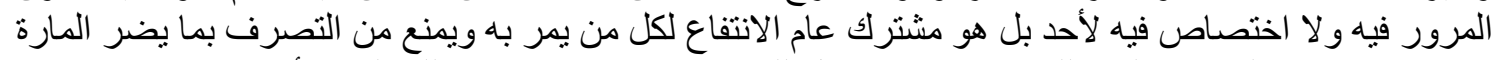

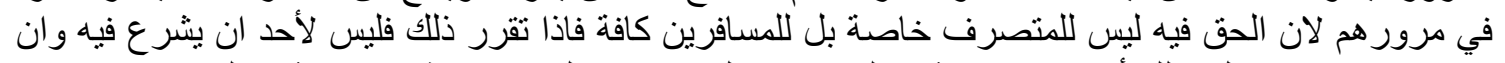

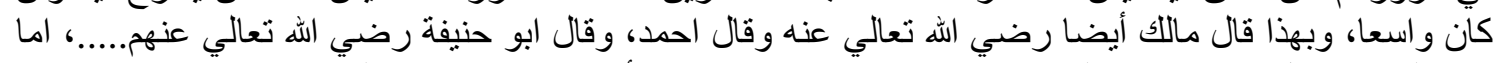

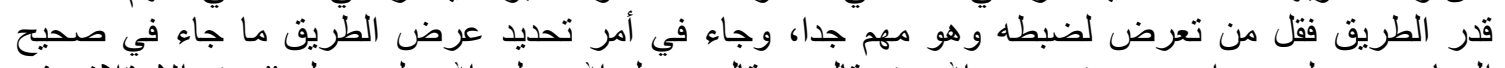

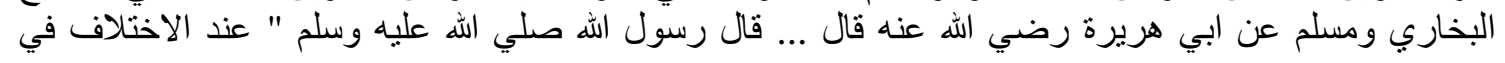




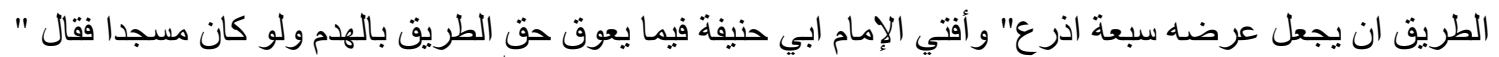

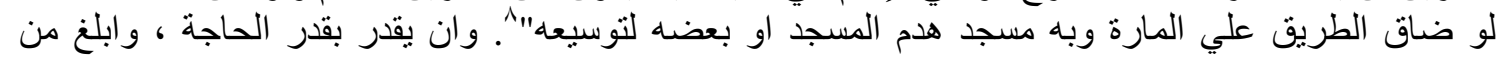

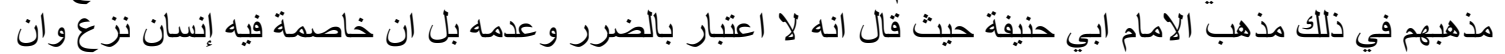

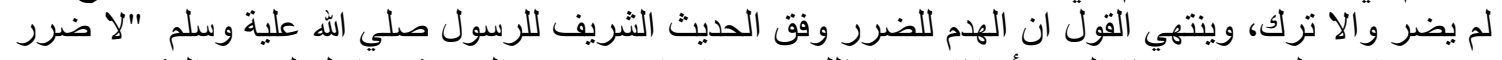

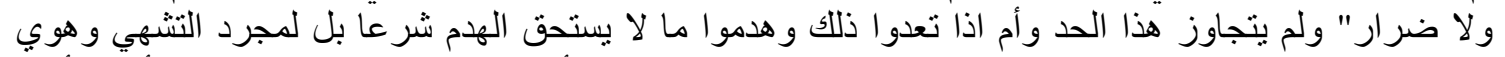

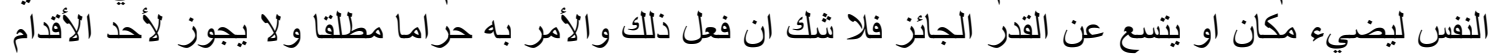

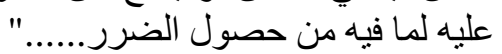

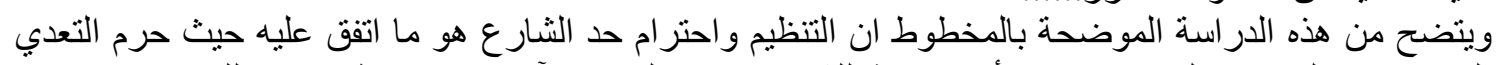

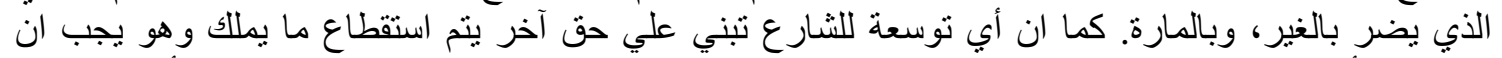

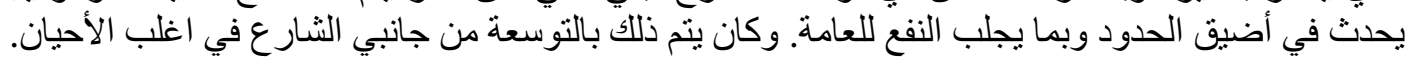

\section{1 ــ آلية إقرار خط التنظيم في العصر الحديث:}

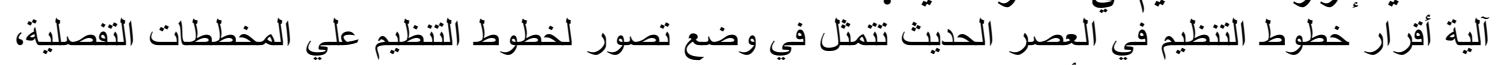

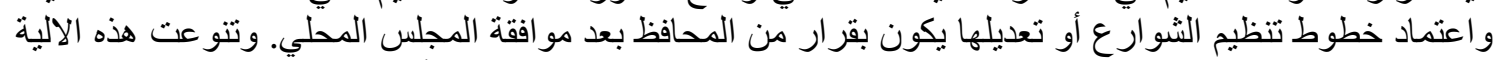

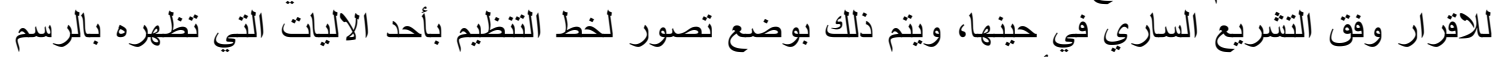

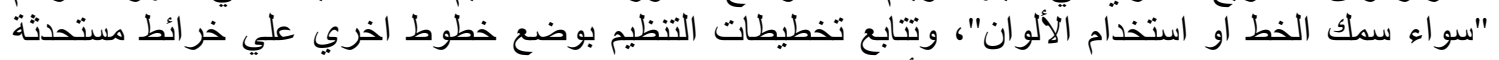

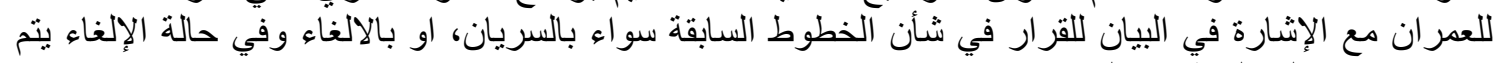

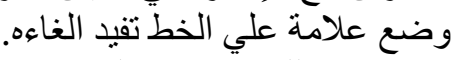

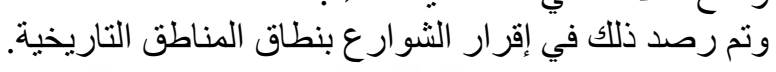

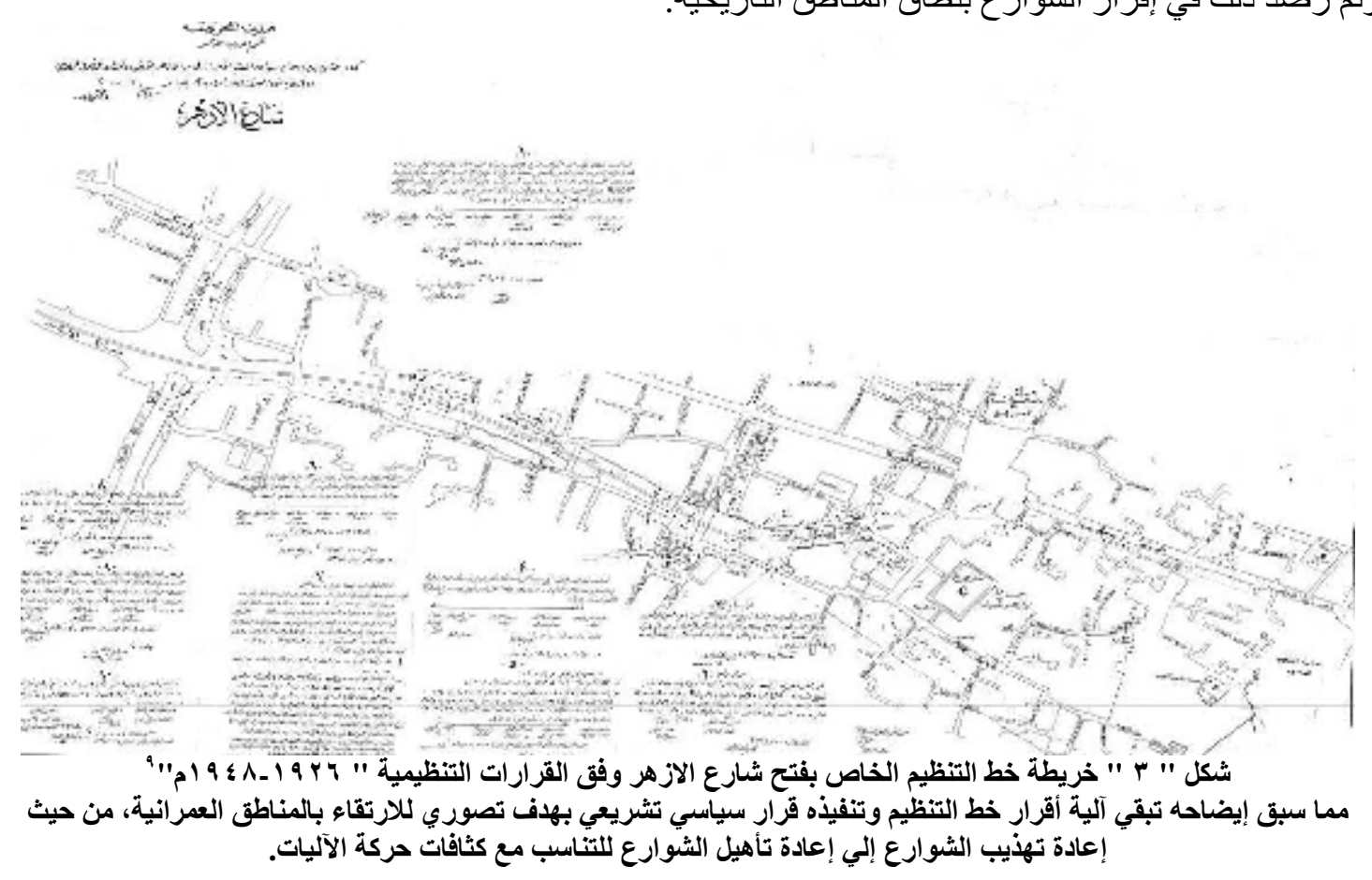

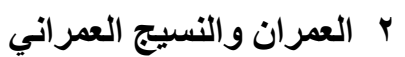

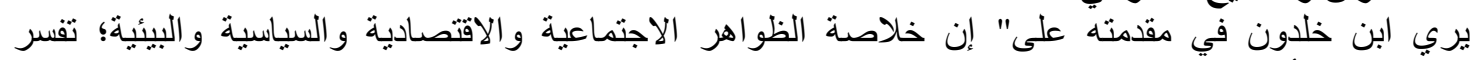

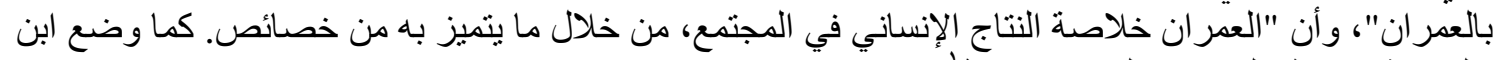

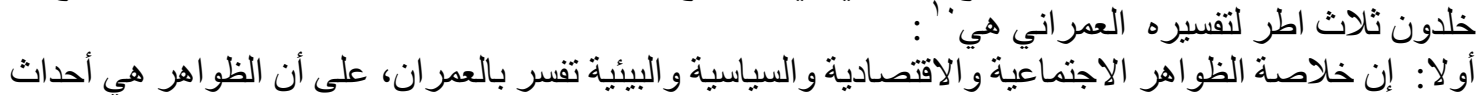

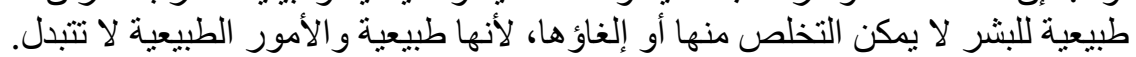

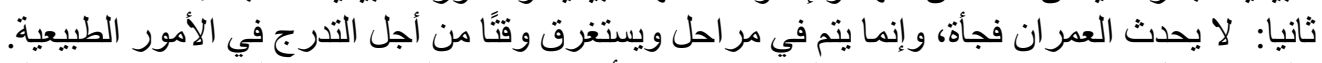

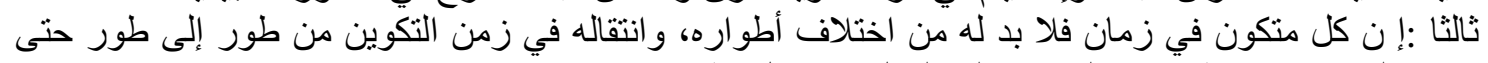

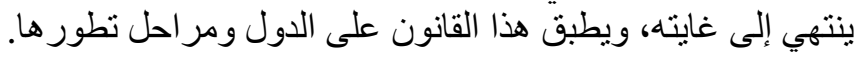

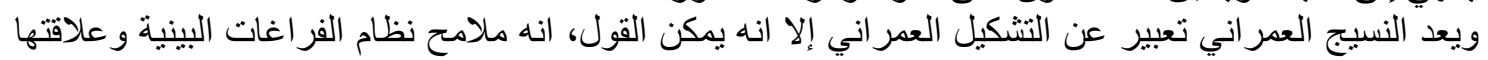

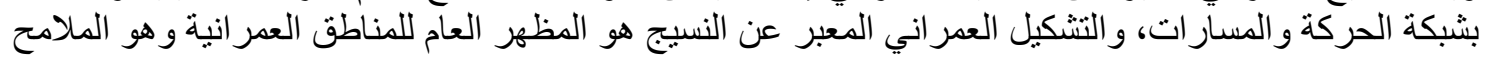




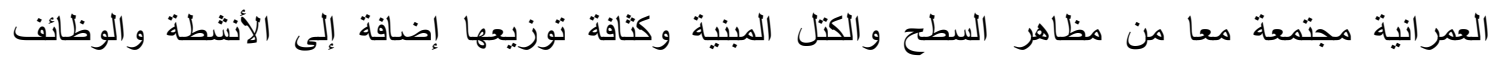

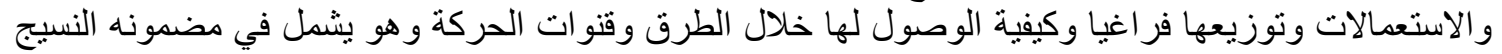
و الفر اغات العمر انية و البيئة المحيطة.

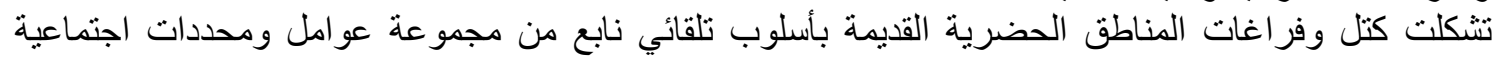

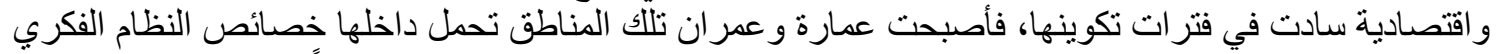

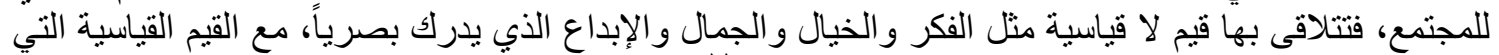

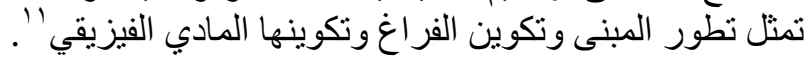

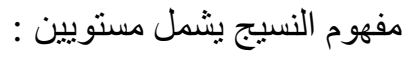

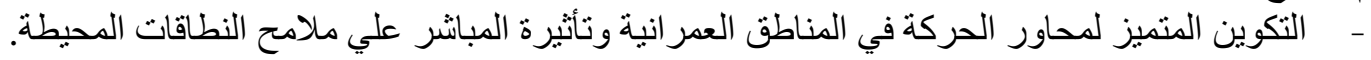

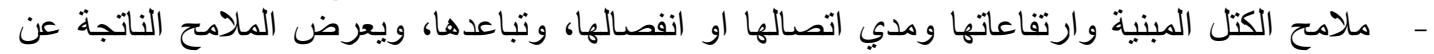
علاقات هذه الكتل بالفراغات الخارجية المحيطة بهات والهات والمحصورة بينها "العلاقة بين الكتل المبنية و الفر اغات البينية، و المفتوحة ".

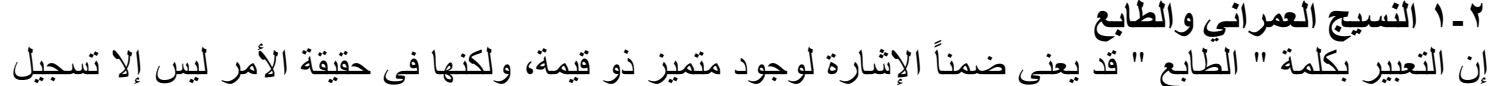

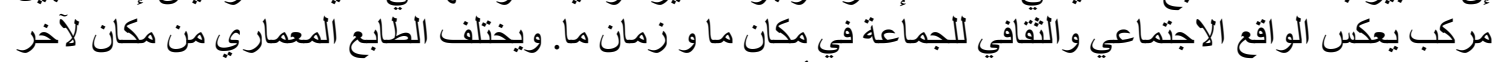

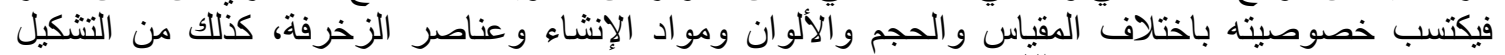

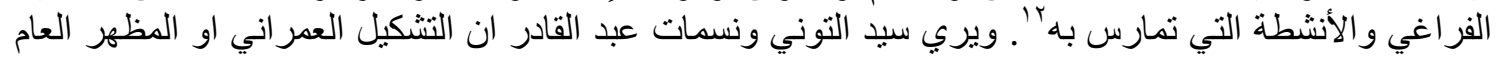

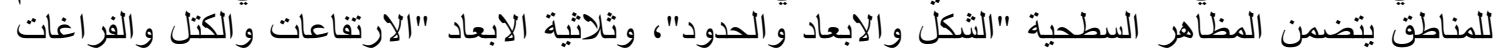

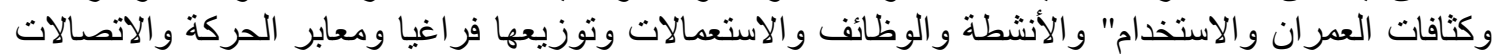

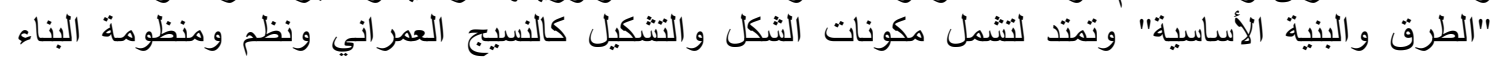

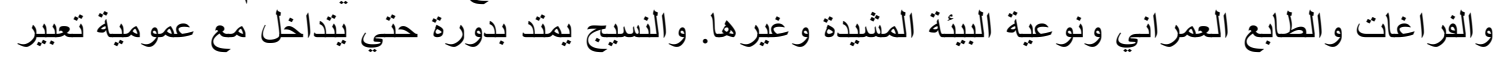

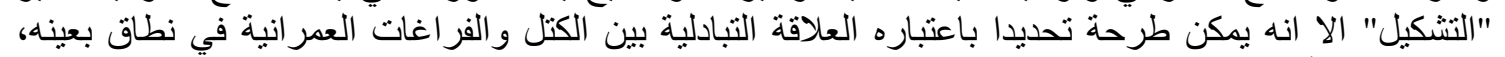

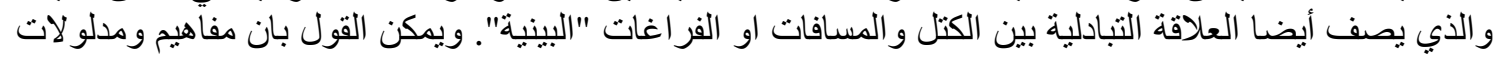

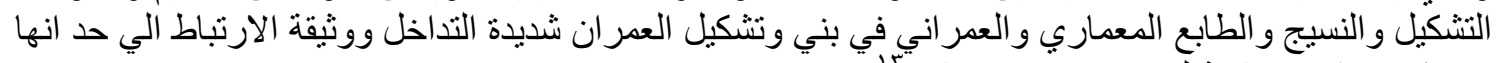

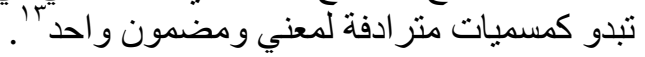

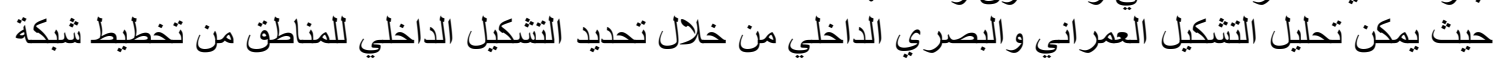

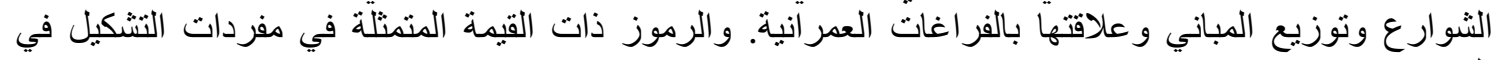

وهناك عناصر تساعد في تحديد الطابع في المناطق العمرانية التراثية مثل:

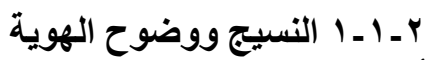

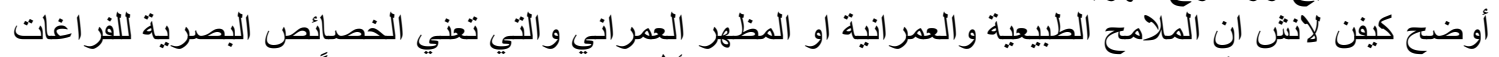

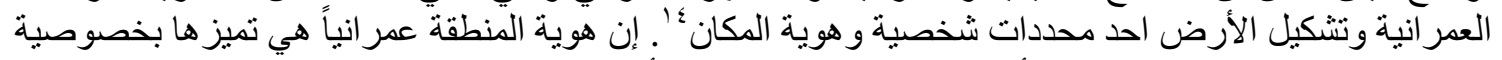

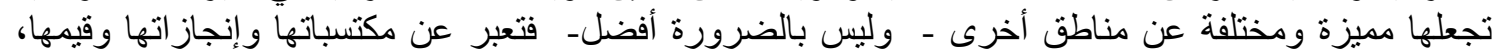

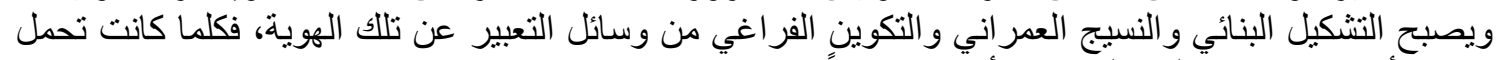

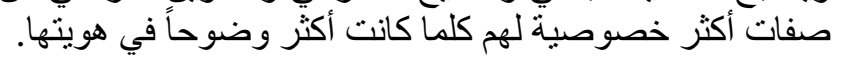

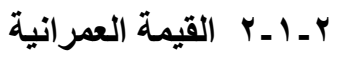

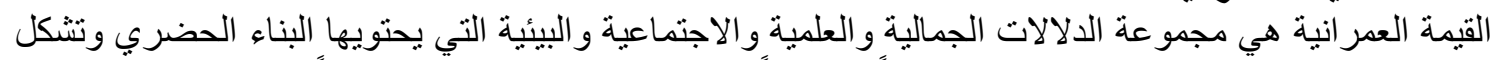

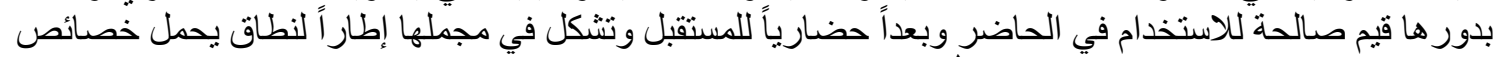

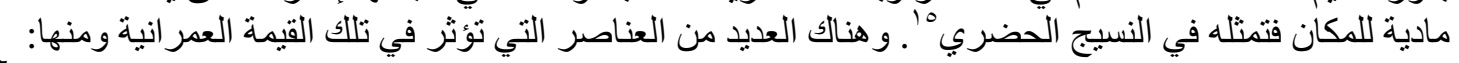

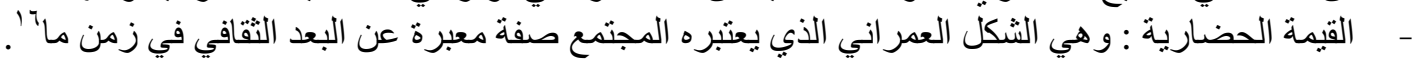

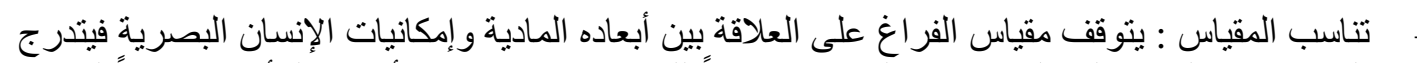

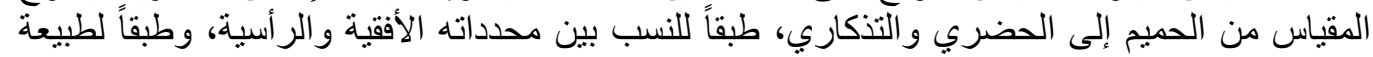

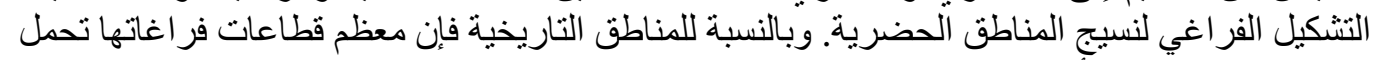

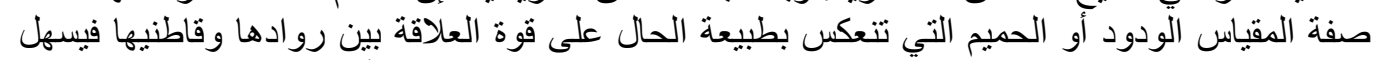

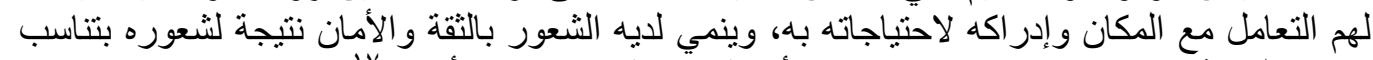

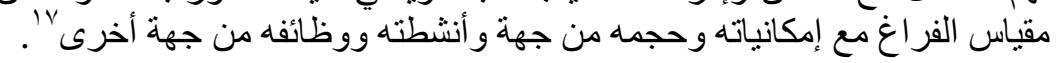




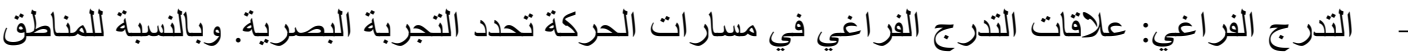

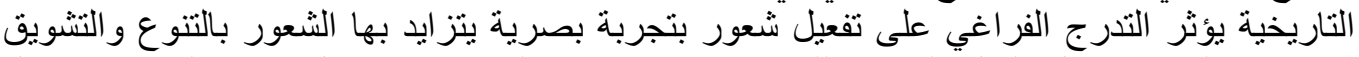

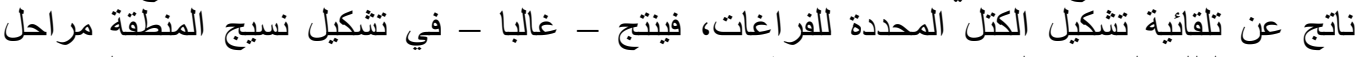

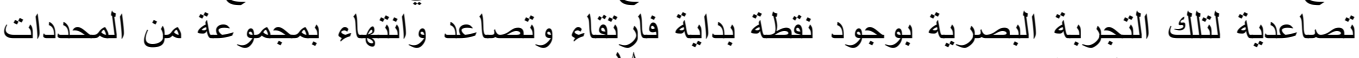

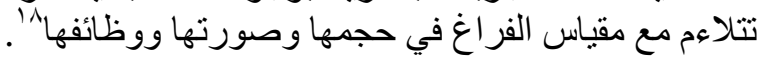

ب بر التراث

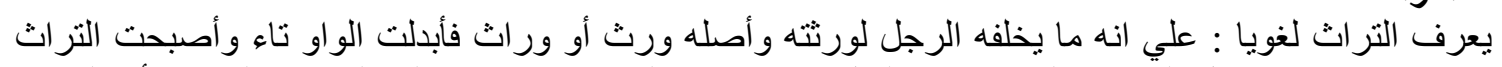

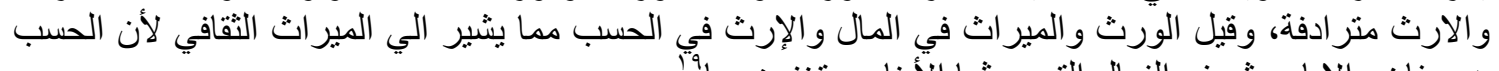

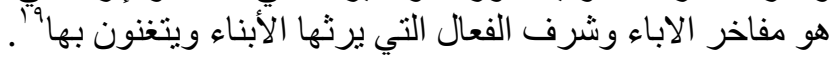

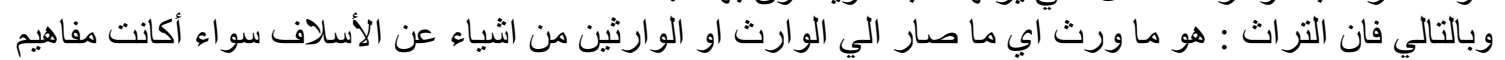

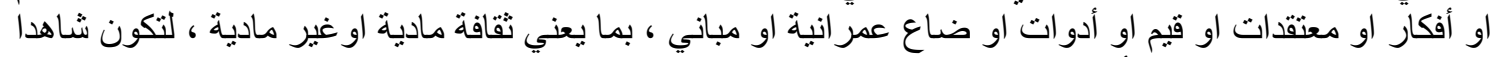

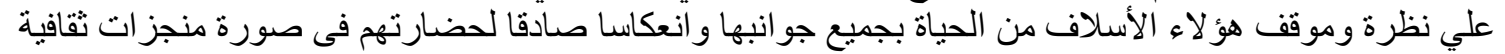

وحضارية. فالتراث هو التجسيد " المتميز " لثقافة لجماعة في حقبة او حقب بعينها" ، و التراث اثلئ هو المرجع و الكيان المادي القائم

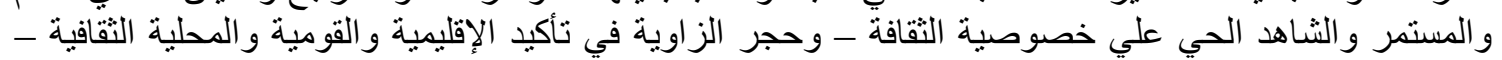

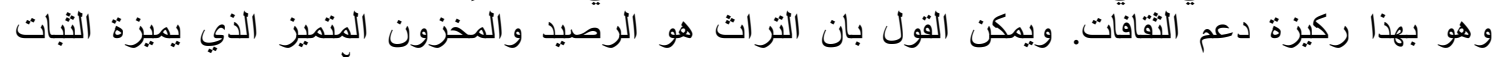

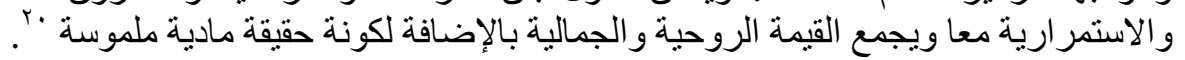

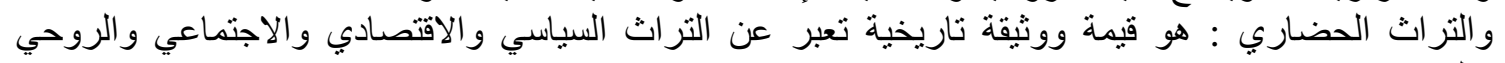
و الرمزي.

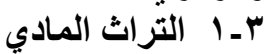
يشمل المباني و الأمَاكن التاريخية والآثار والتحف وغير ها، التي تعتبر جديرة بحمايتها والحفاظ عليها بشكل أمثل

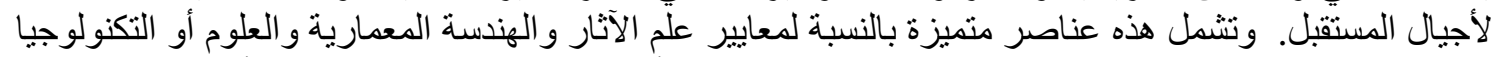

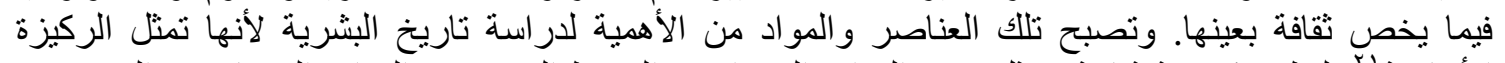

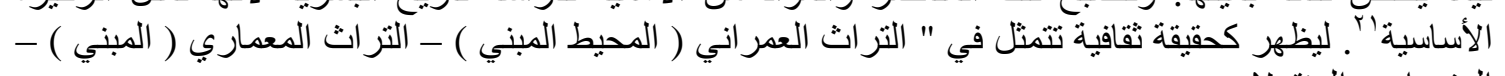

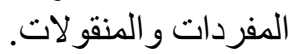

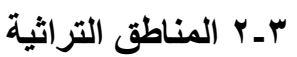

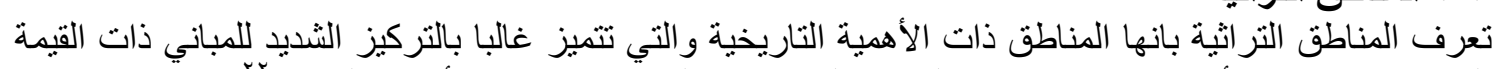

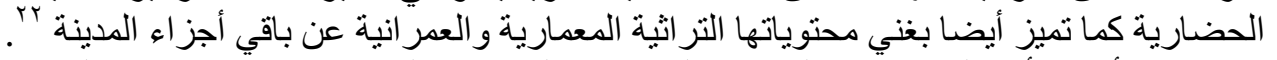

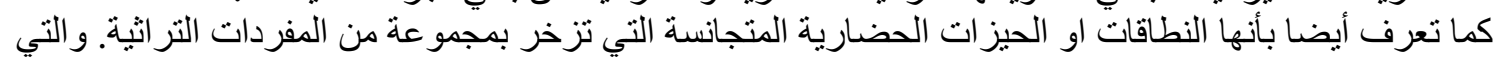

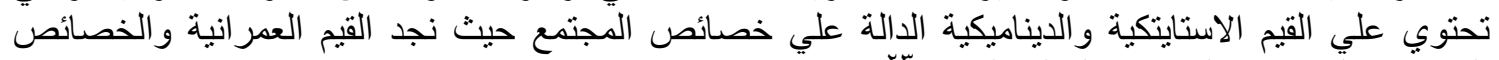

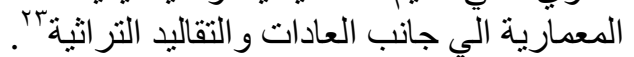

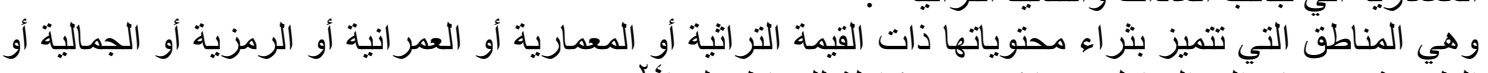

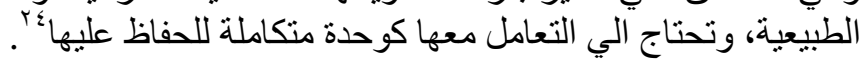

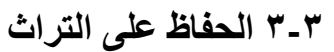

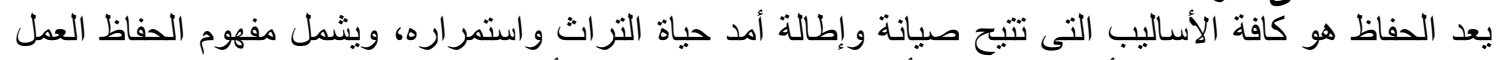

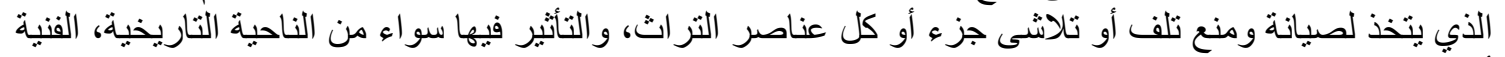

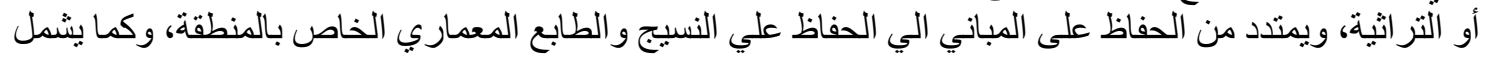

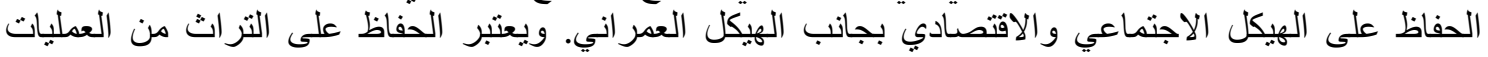

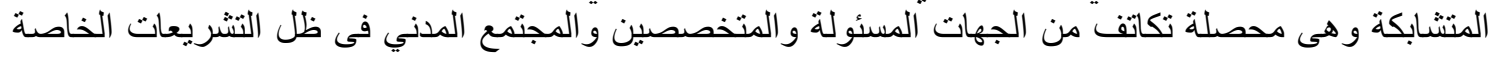

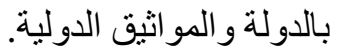

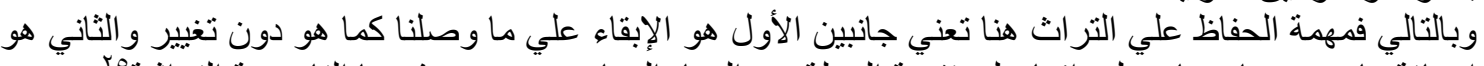

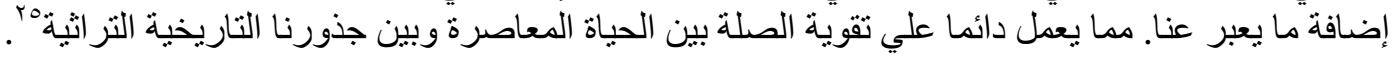

بـ ـ المناطق التراثية والمواثيق الدولية:-

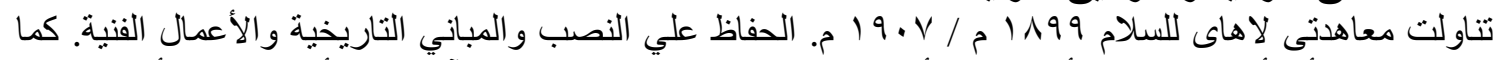

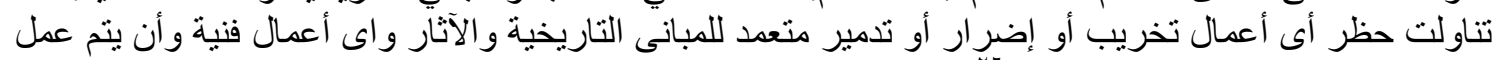

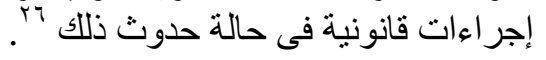




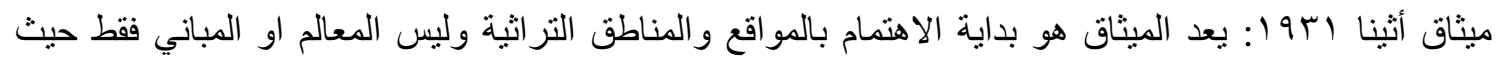

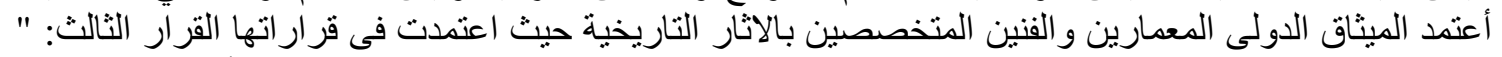

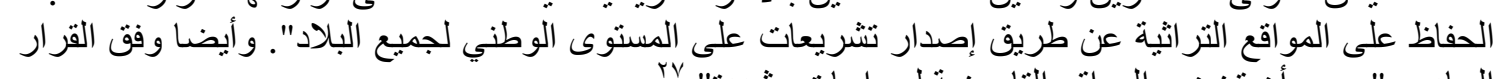

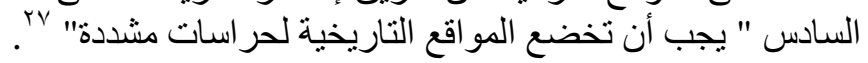

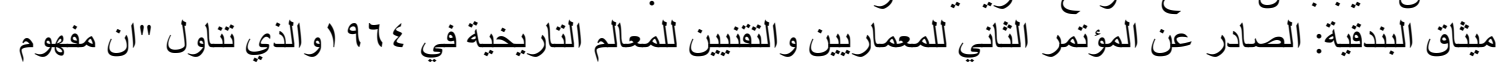

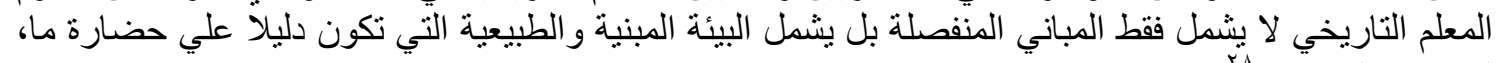

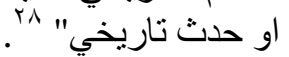

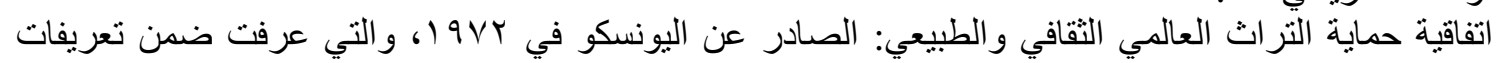

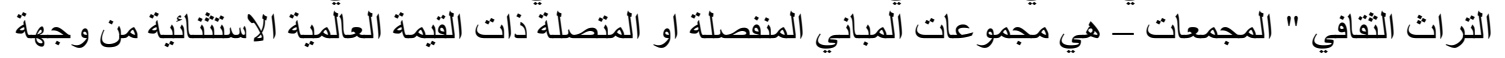

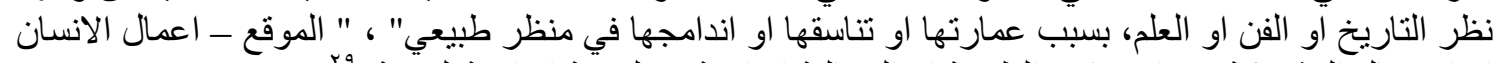

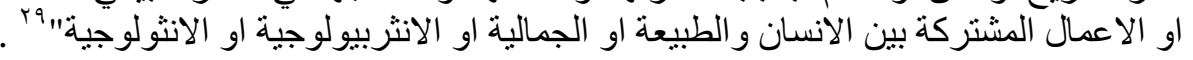

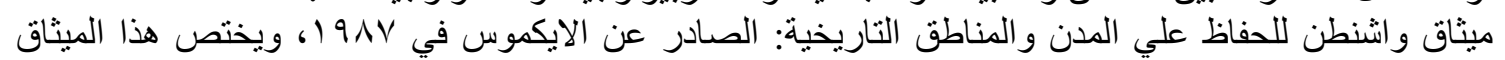

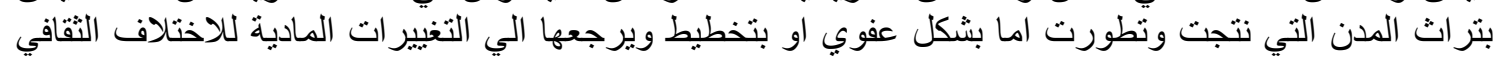

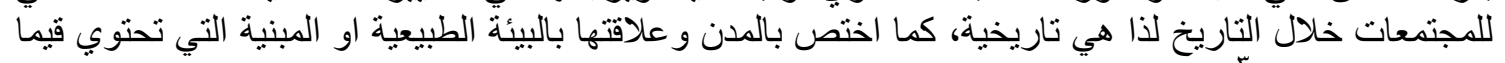

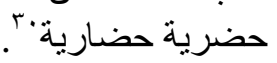

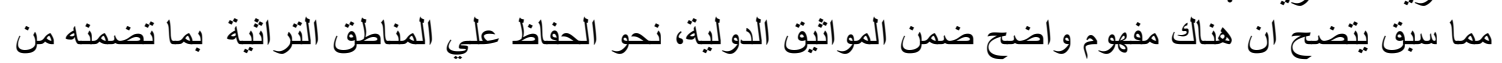

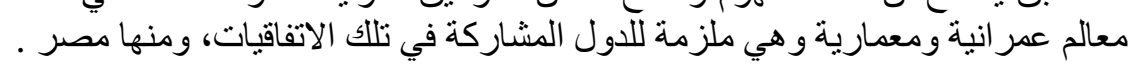

ع الدراسة التطبيقية : اثار تطبيق خط التنظيم:

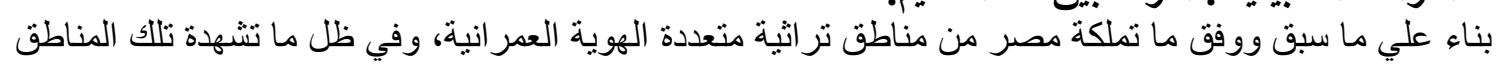

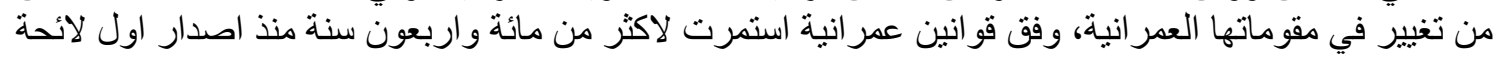

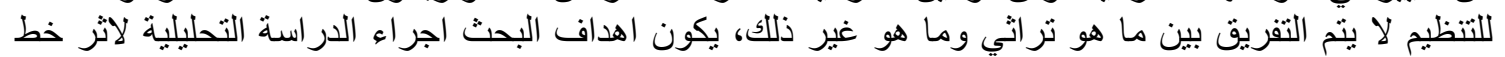
التظيم علي المناطق التر اثنية.

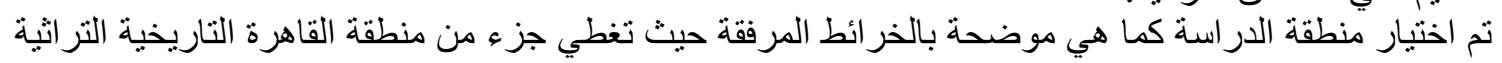

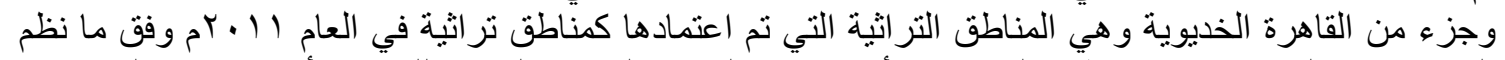

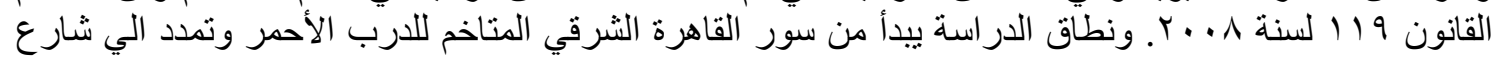

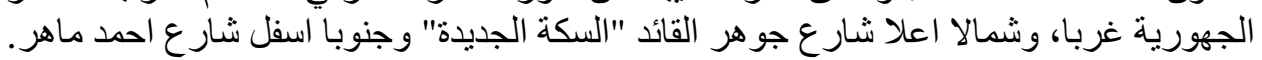

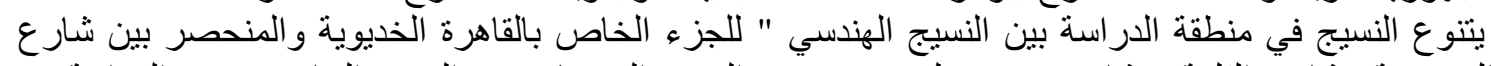

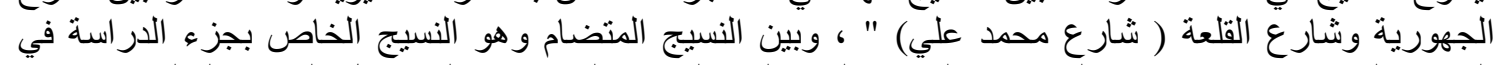

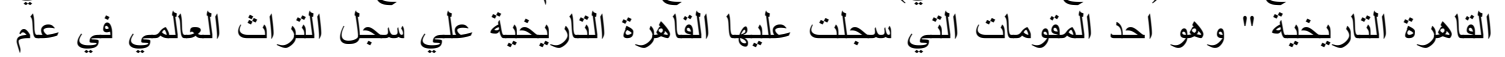

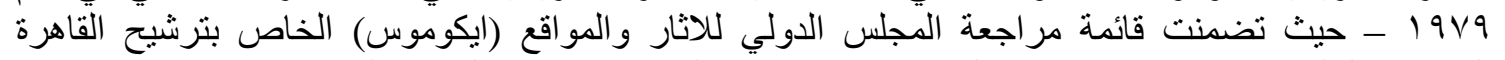

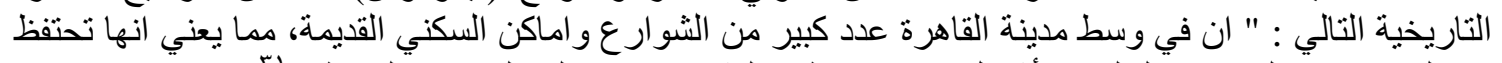

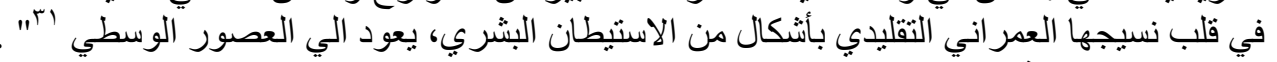

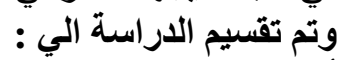

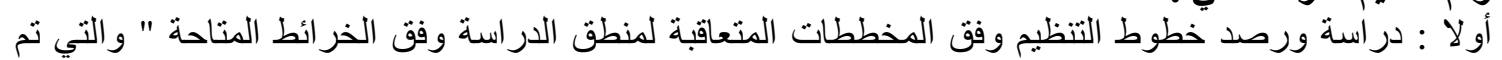

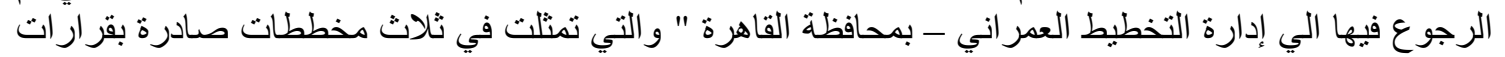

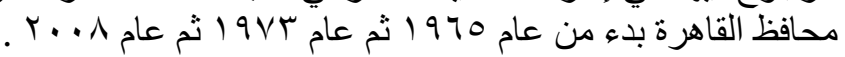

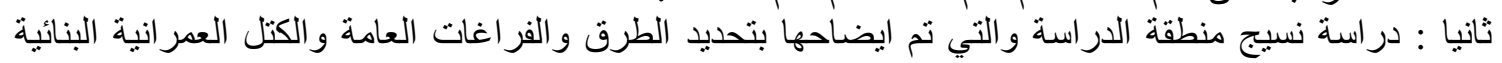

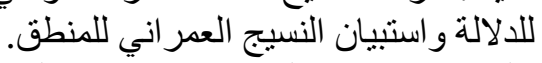
ثالثا: دراسة ما يخلفة تطبيق خطوط التئيق التنظيم من حذف للنسيج ، وكذلك دراسة اثر تغيير تشكيل شبكة الطرق وفق خطوط التنظيم المعتمدة علي تشكيل النسيج العمر انئي. رابعا: در اسة علاقة خط التنظيم بزو ائد وضو ائع التنظيم وما لها من تغيير في شكل وحدود الثو ارع و الكتلة البنائية. 
خامسا : دراسة علاقة خط التنظيم بالمباني التراثية والاثرية.

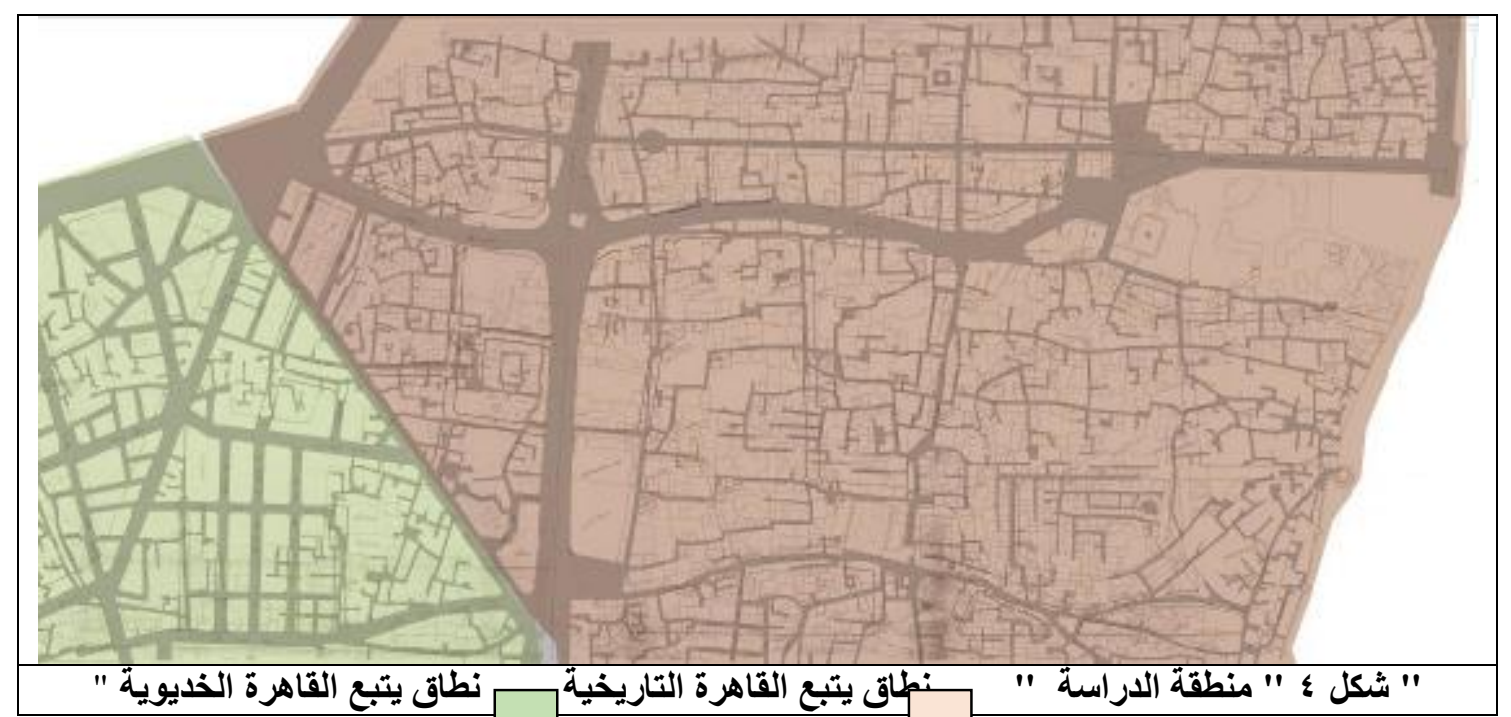

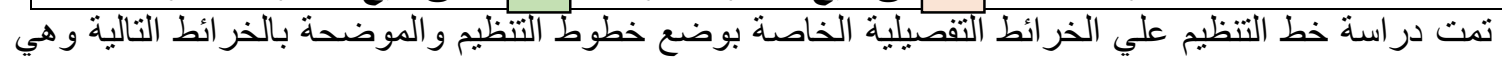

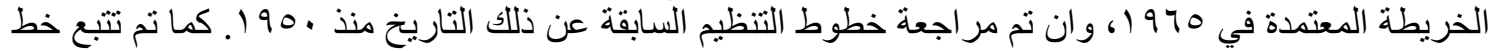

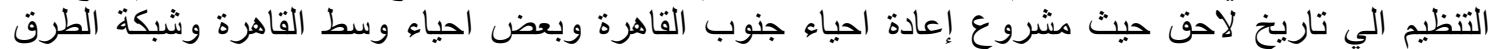

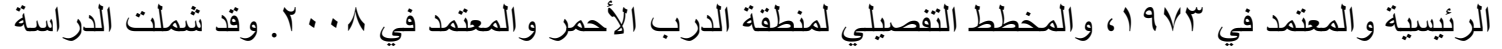
الإشارة الي خطوط التنظيم الملغاة والتي تم الإشارة لها بوضوح بوضع علامات الإلغاء المتعارف عليها علي تلألك

الخطوط.

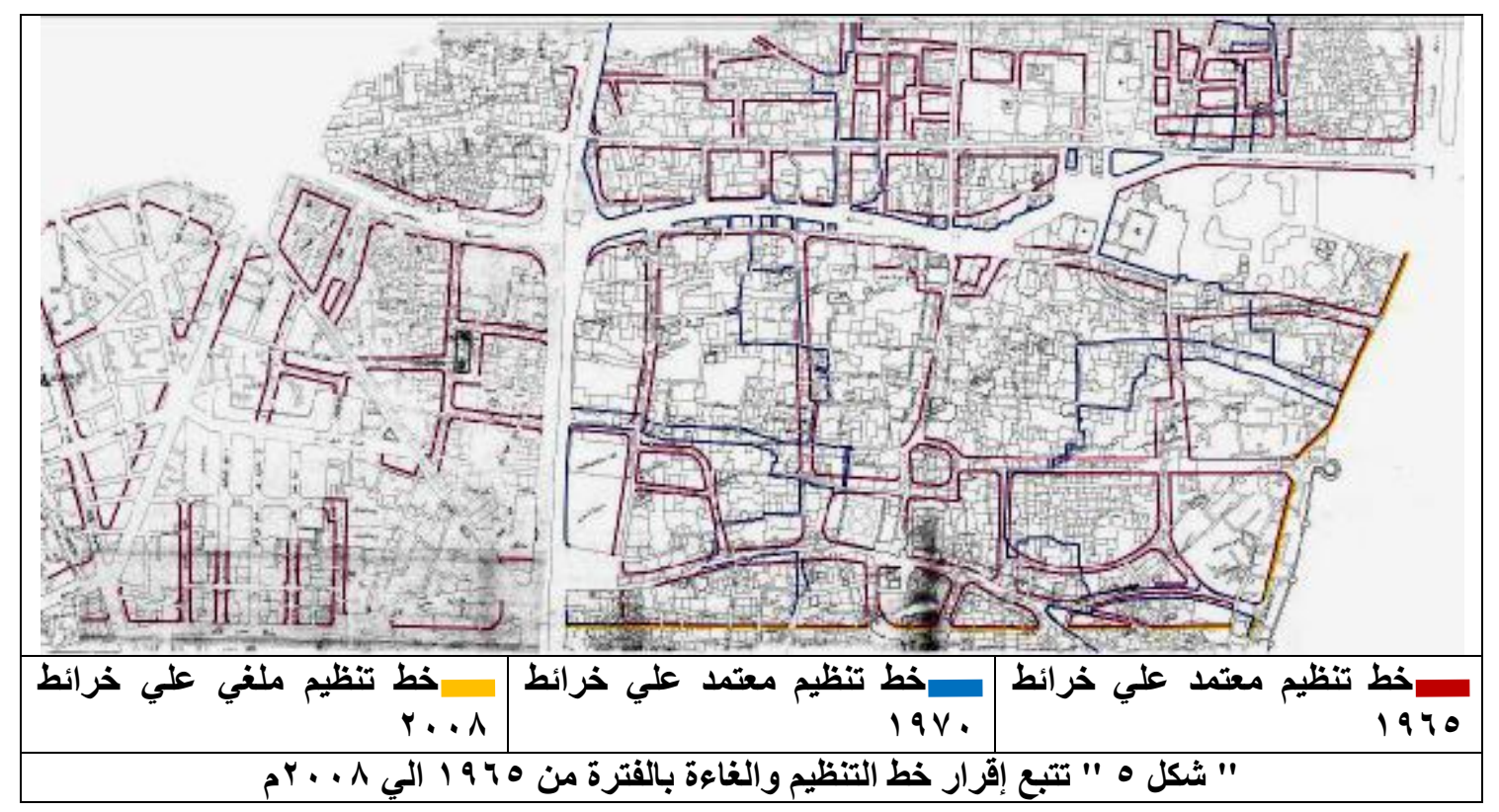



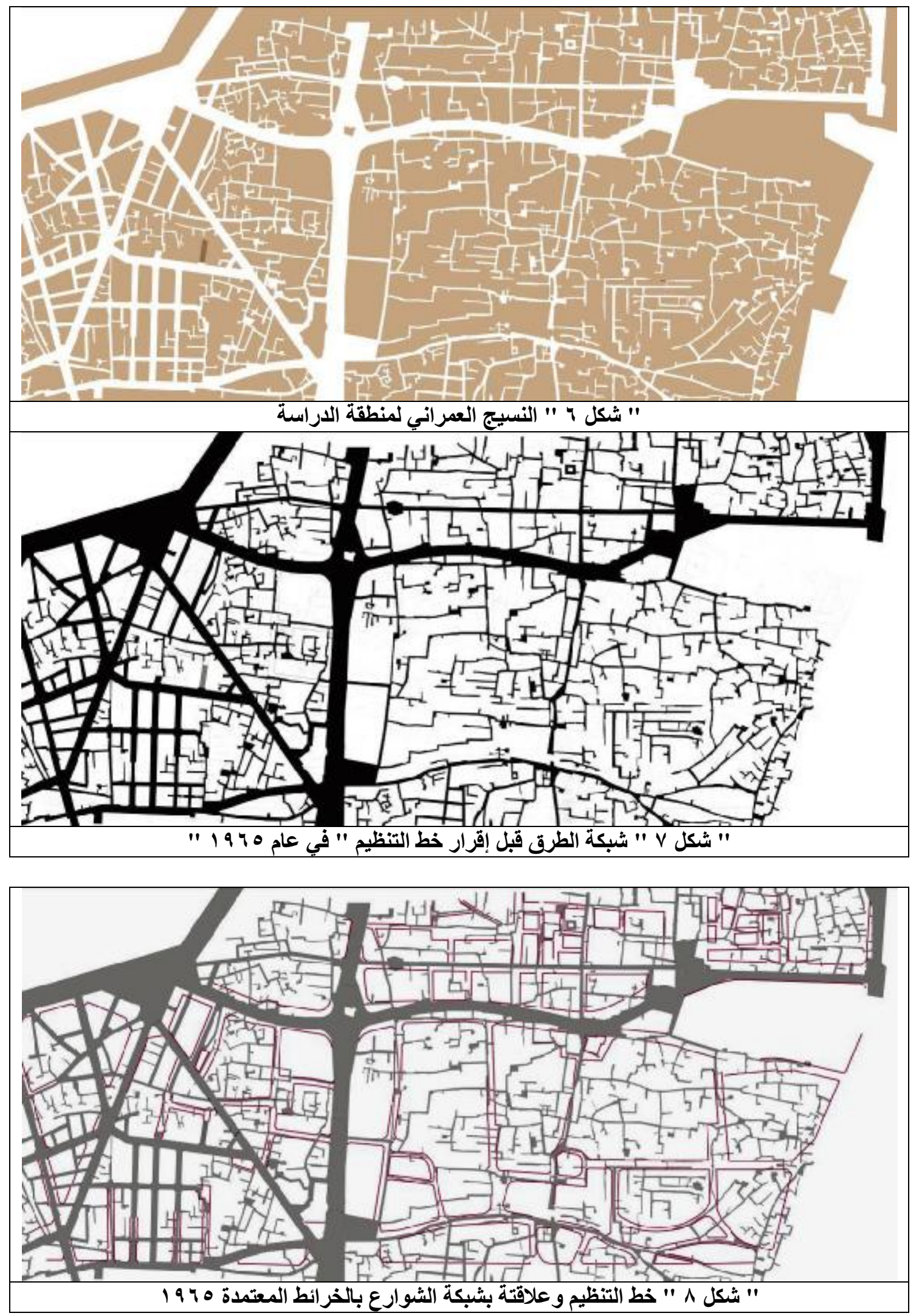


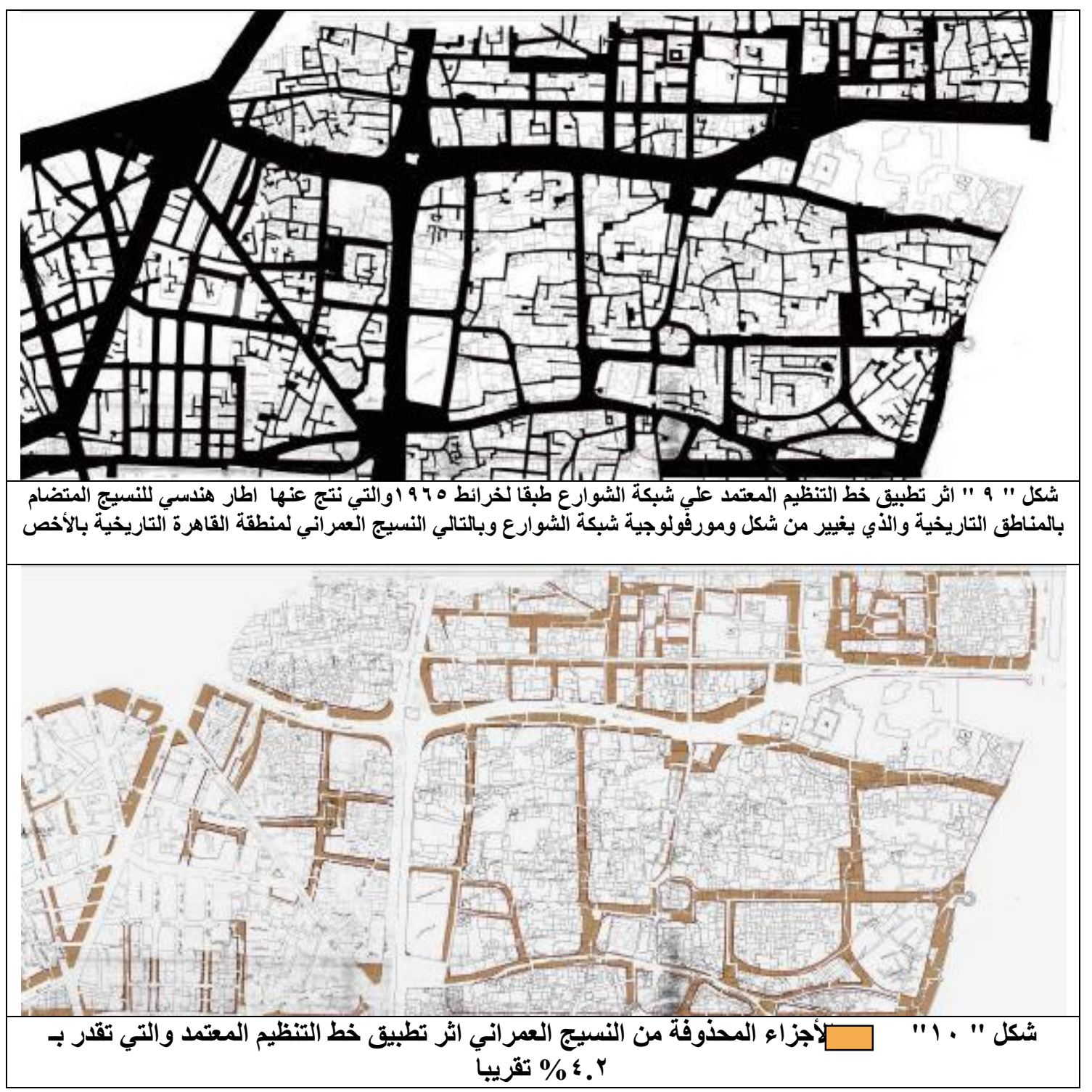




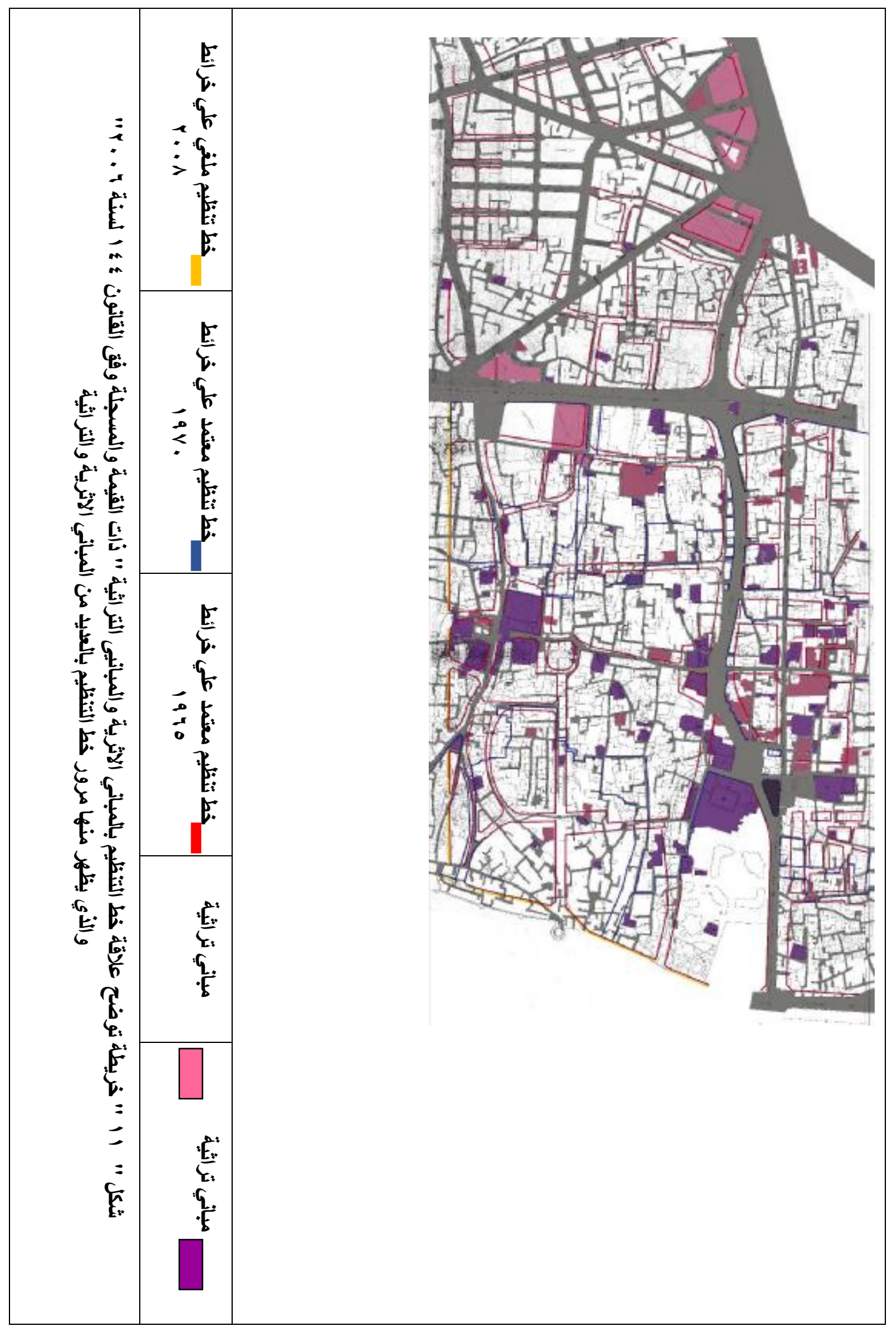




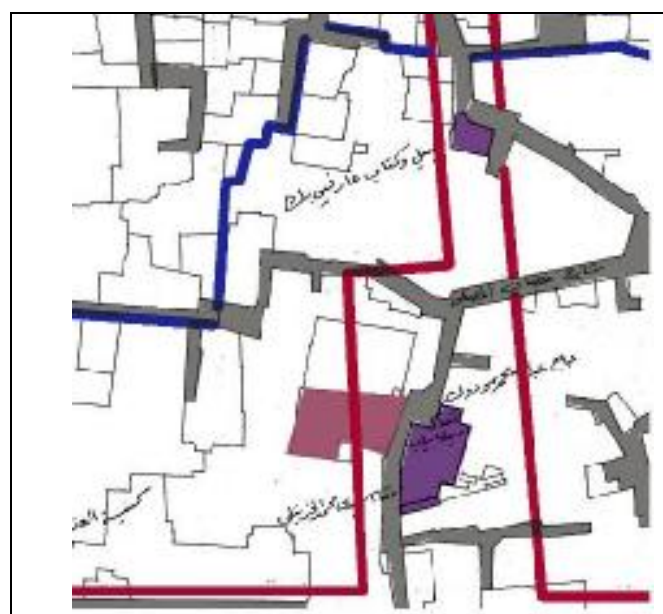

شكل " بر ا " تواجل مباني اثرية في مسار الطرق المفتوحة

بواسطة خط التظيم ، ومرور خط التنظيم بمباني تراثية

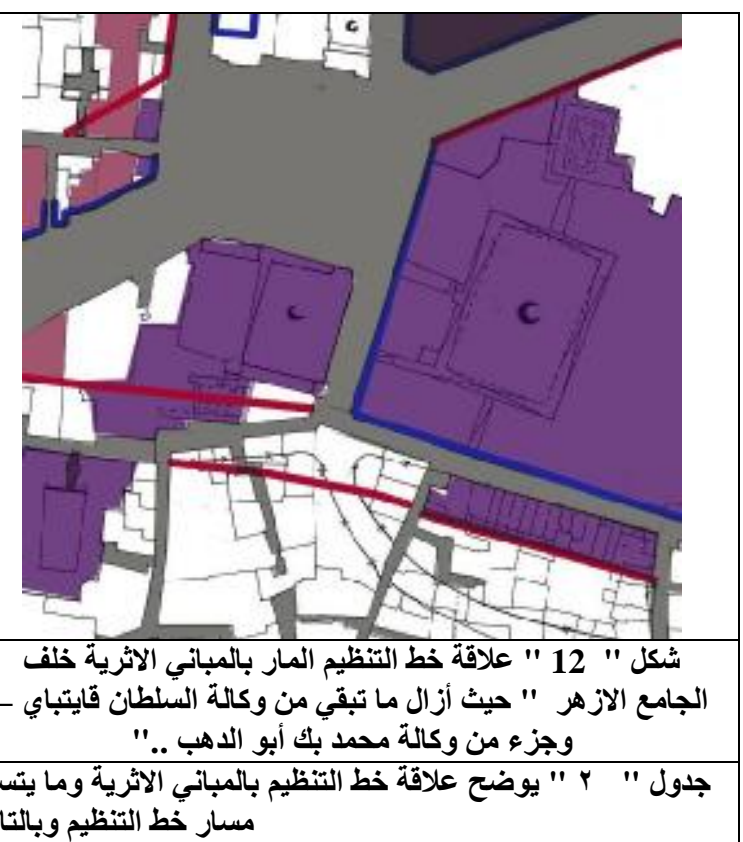

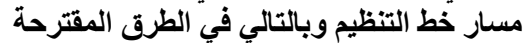
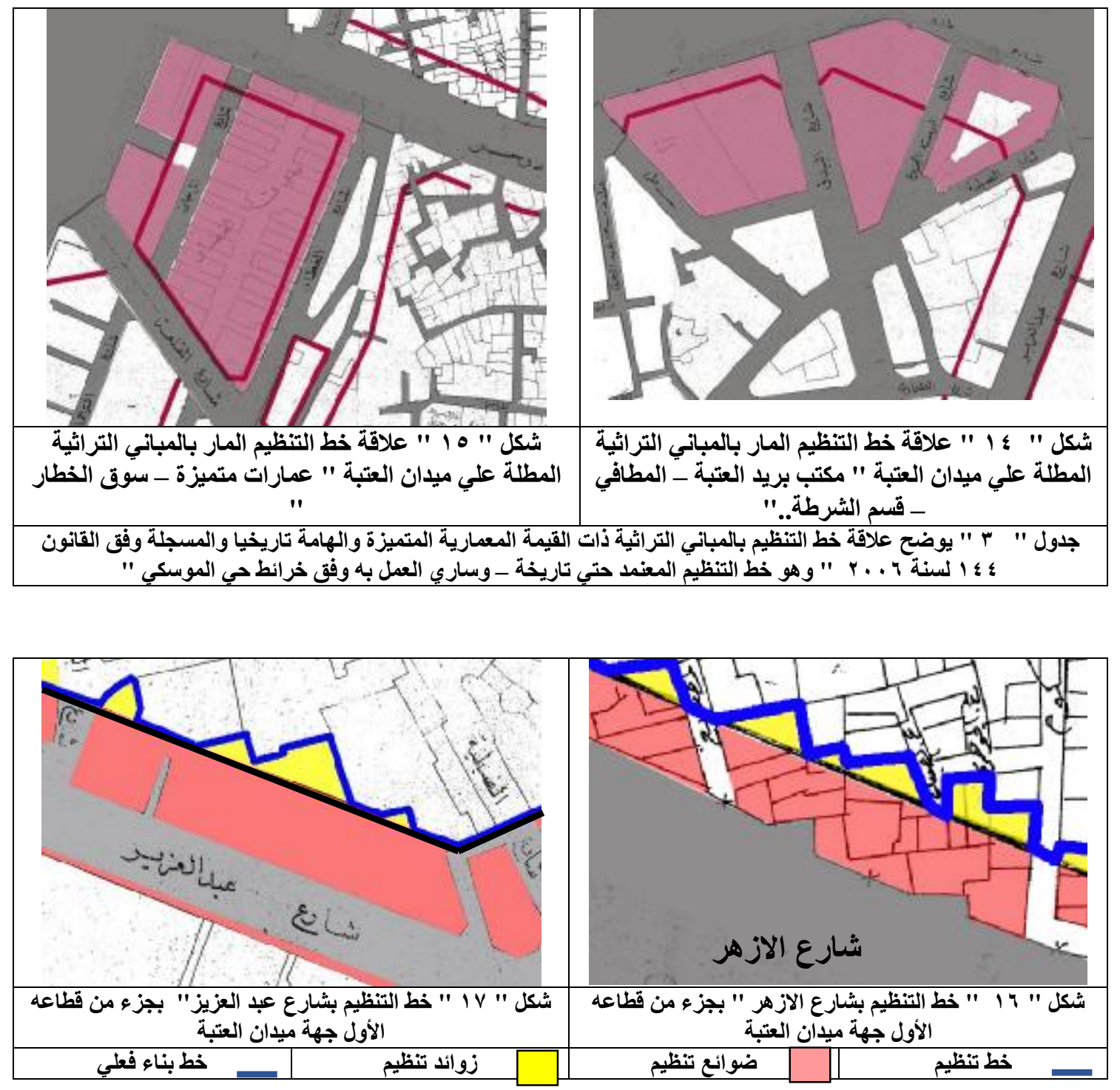
جدول " ؛ " بوضح اثر خط التظيم علي الاراض باية من شارعي العتبة والازهر جهتي ميدان العتبة وما فيا

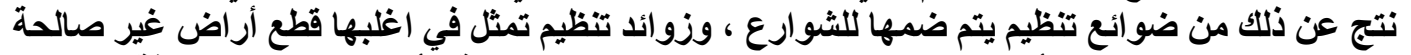

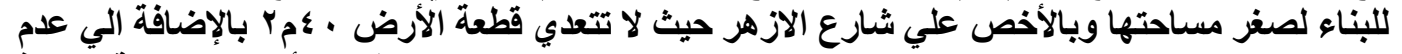

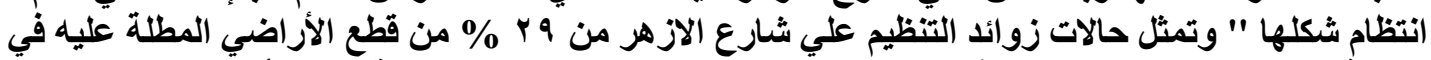

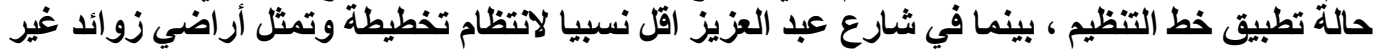

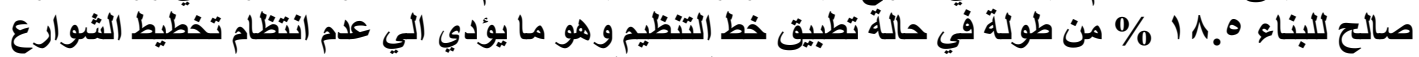
والكتل البنائية المطلة عليه

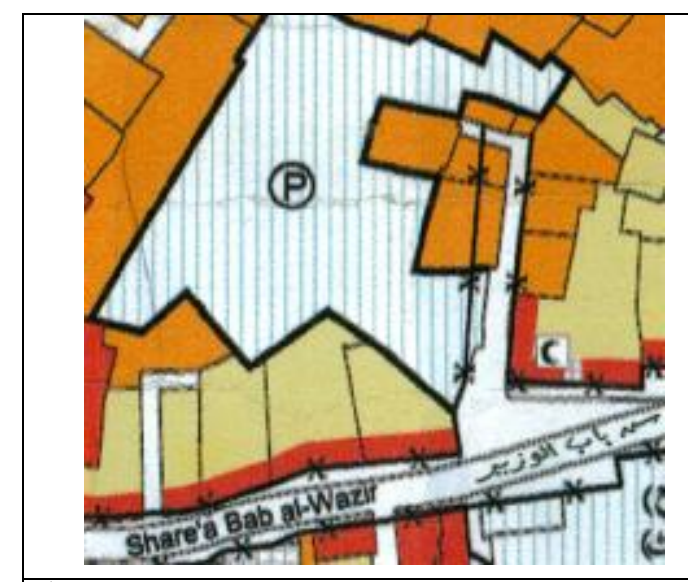

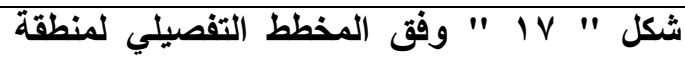

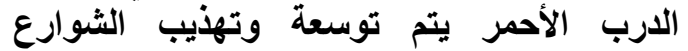

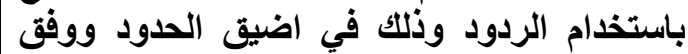
شكل الشارع وبما لايؤثر علي النسيج النئ

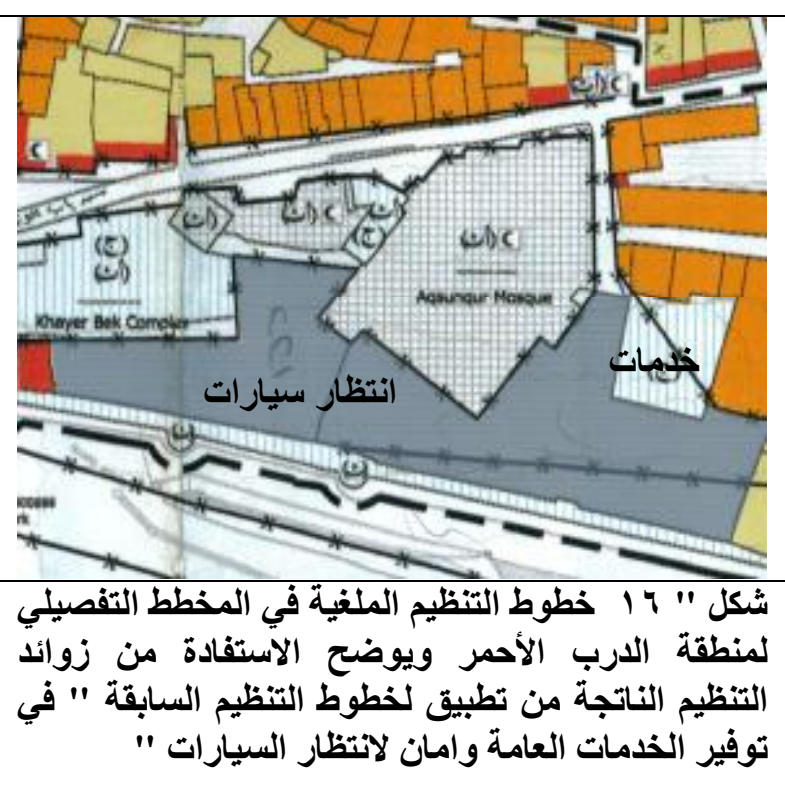

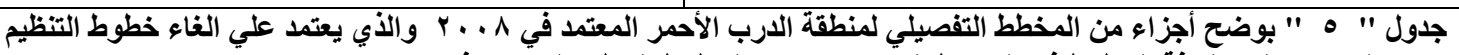

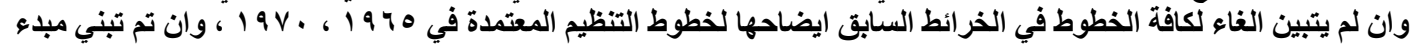

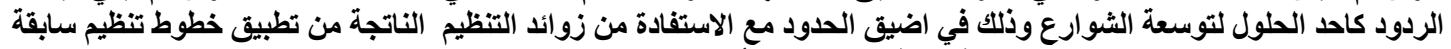

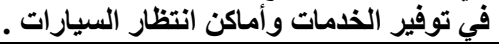

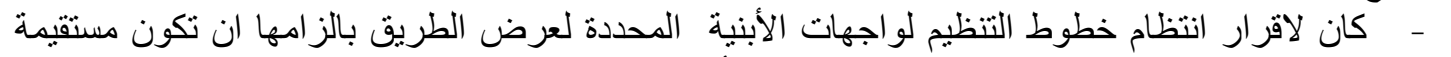

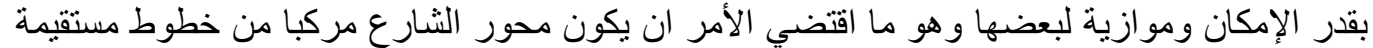

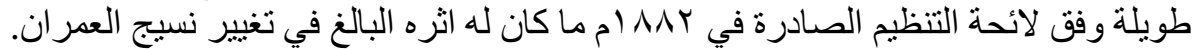

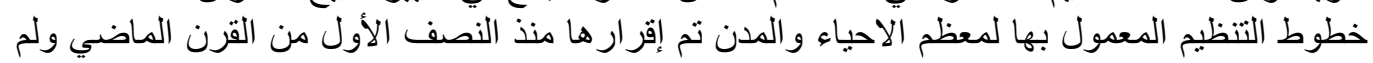

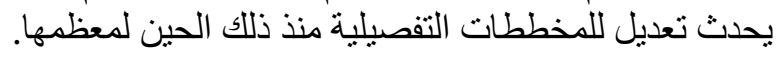

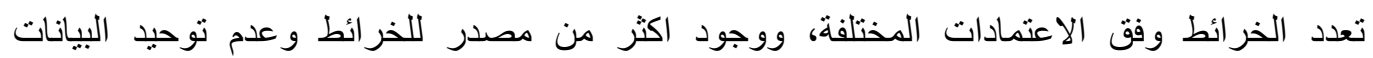

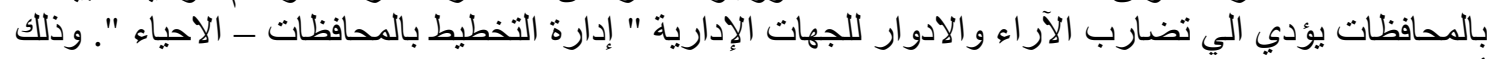

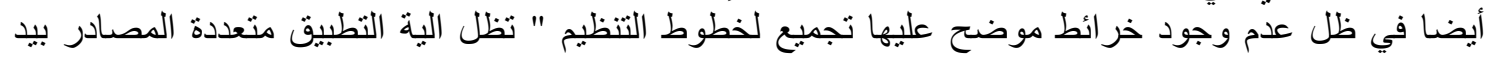

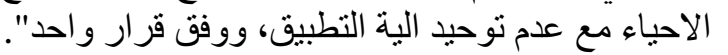
- يصعب تتبع خطوط التنظيم لتهاللك الخرائط بالاحياء وعدم وجود خرائط رقمية موقع عليها خطوط

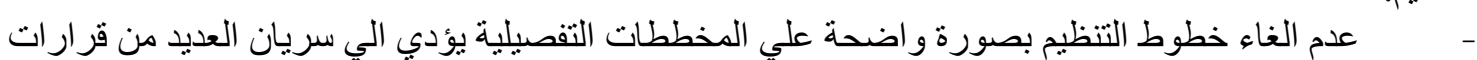

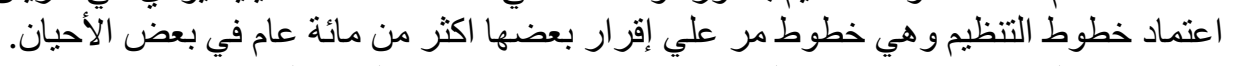

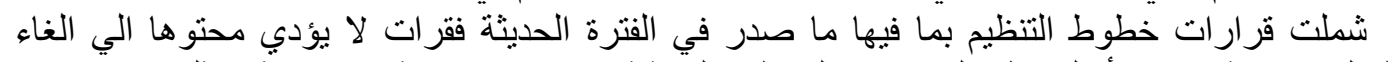

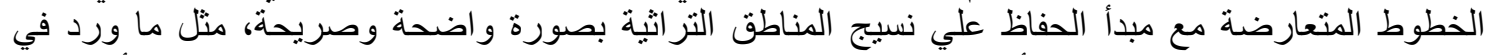

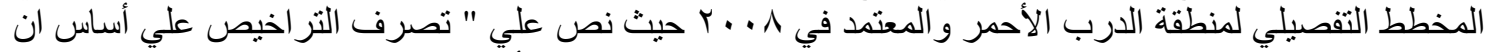

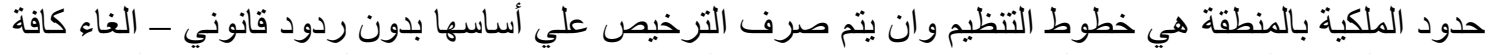

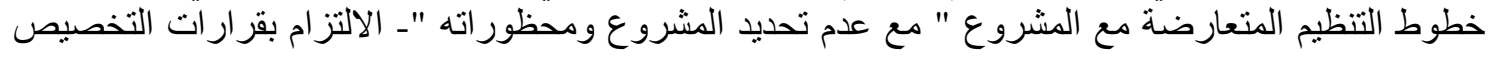


السابقة وخطوط التنظيم المعتمدة غير المتعارضة مع المشروع " ـ و هو ما يؤدي الي عدم الوضوح لمتخذ القرارات

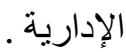

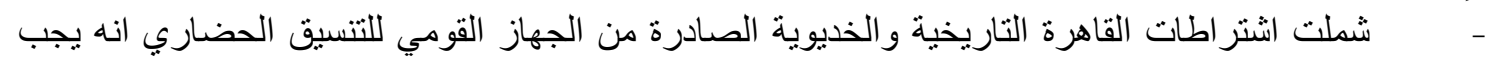

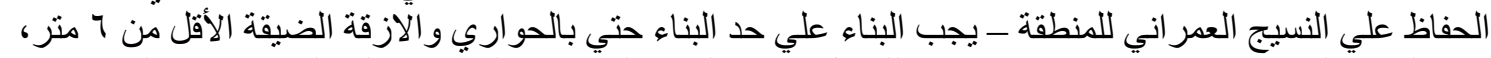

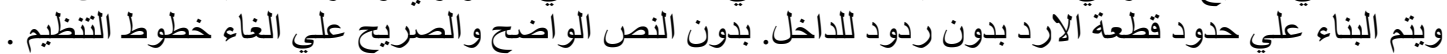

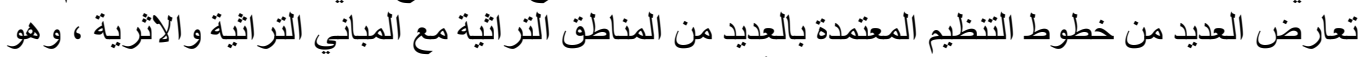

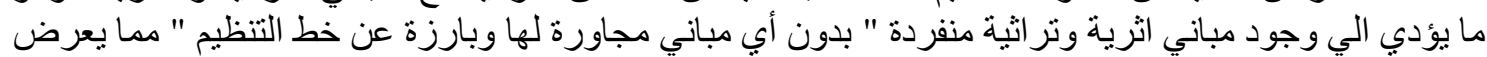

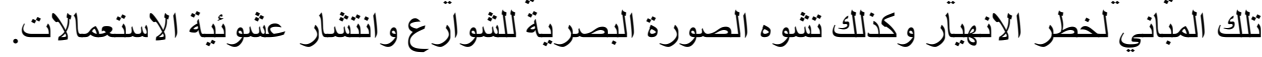

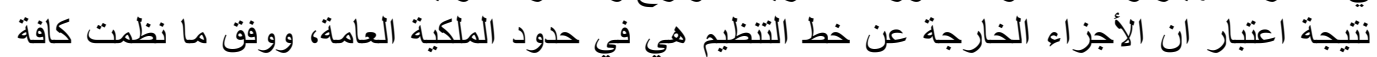

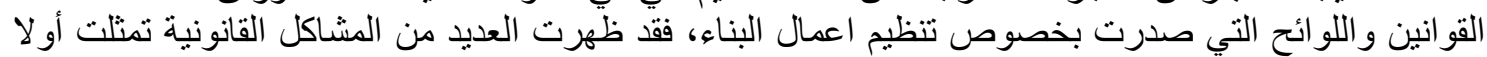

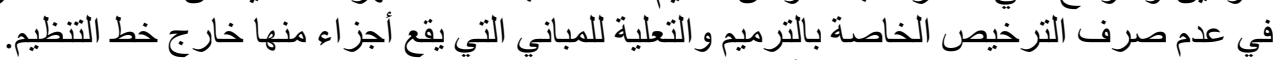

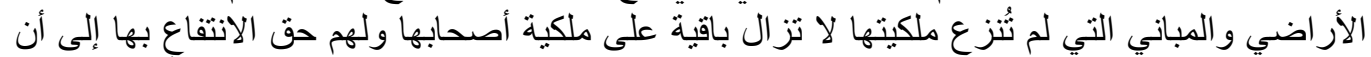

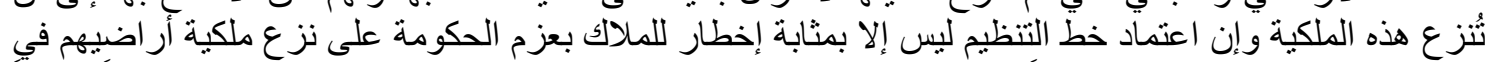

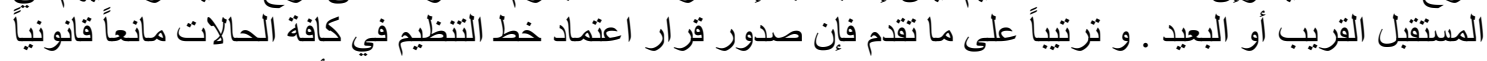

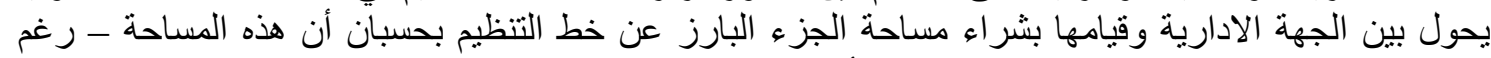

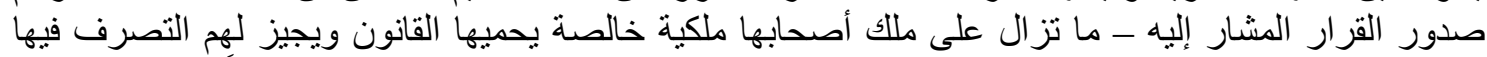

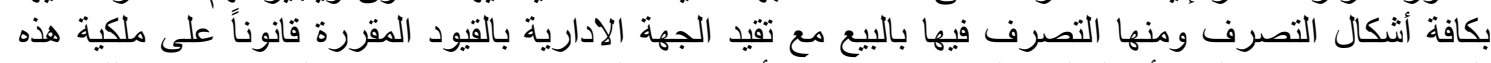

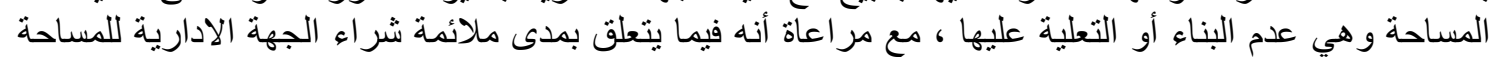

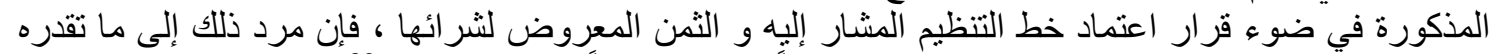

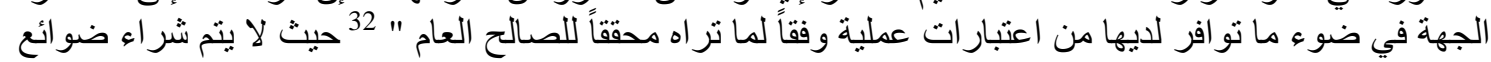

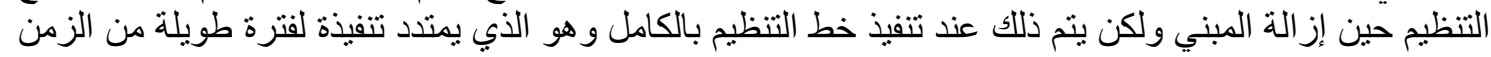

تمدد لعقود.

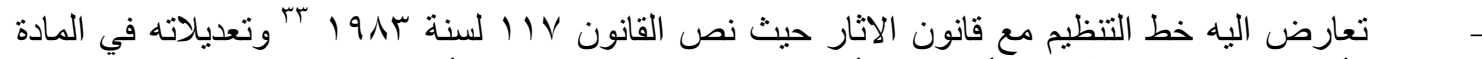

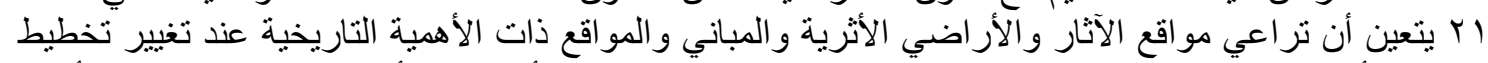

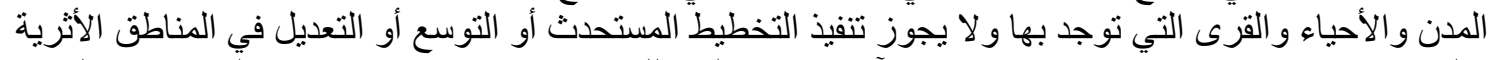

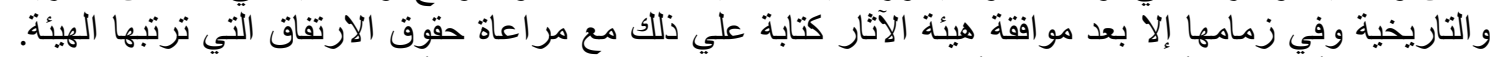

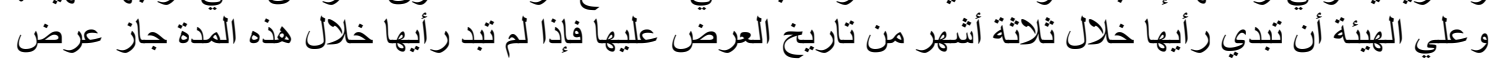

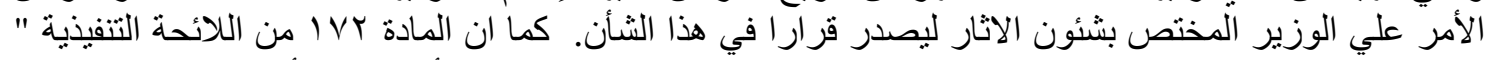

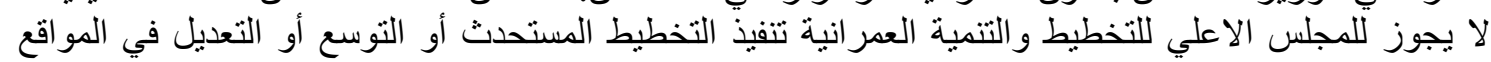

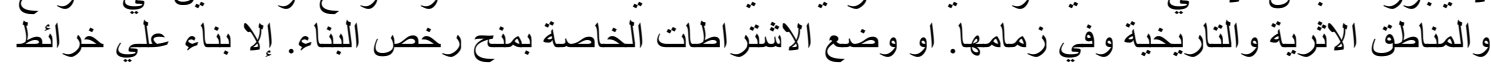

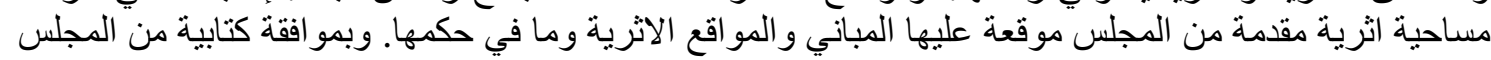

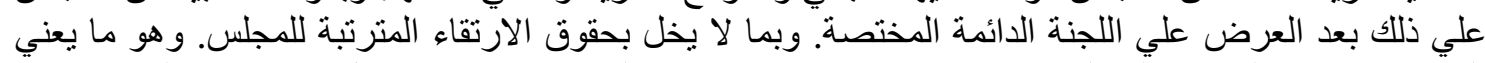

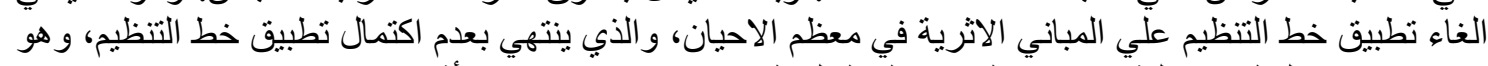

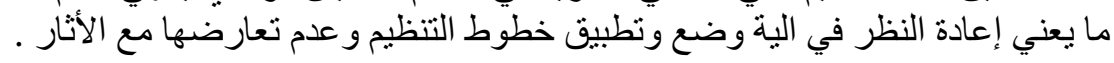

إلغاء كافة خطوط التنظيم بالمناطق التراثية، وذللك بصور واضحة علي خرائط معنية بذلك الثأن

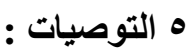

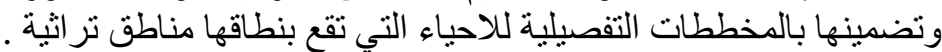

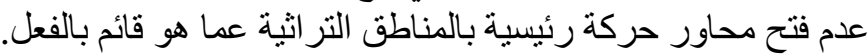

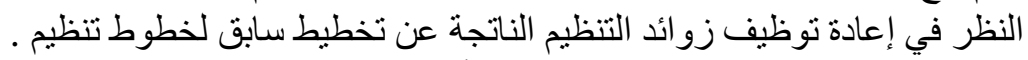

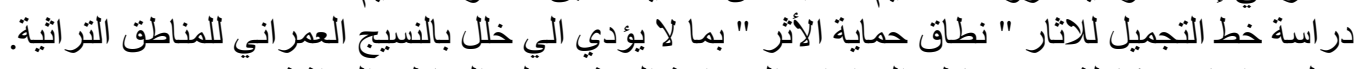

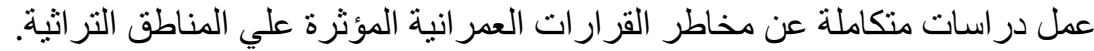

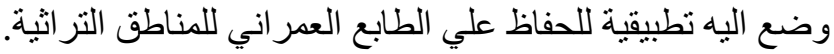

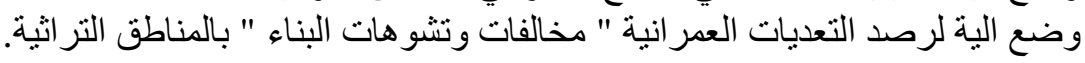


1. https://commons.wikimedia.org/wiki/Category:Old maps of Cairo

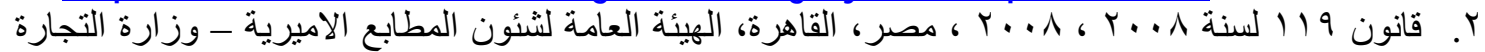
و و الصناعة.

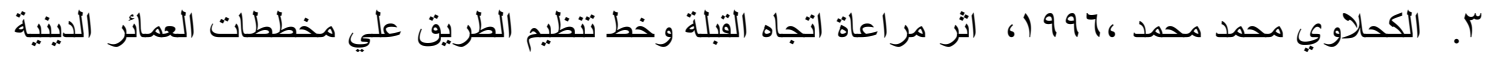

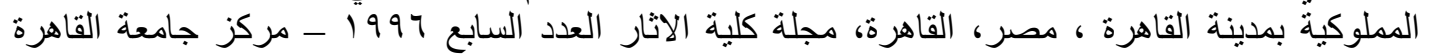
للطباعة والنشر ، جامعة القاهرة.

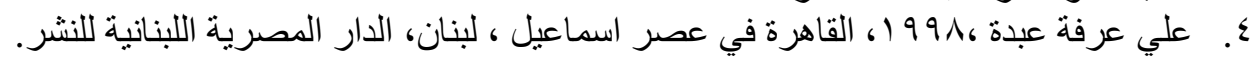

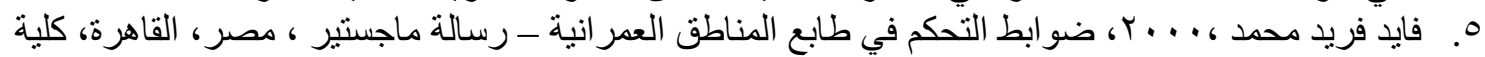

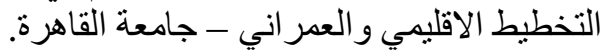

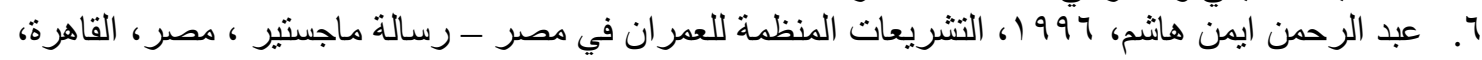

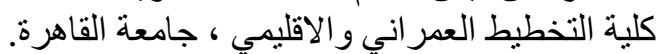

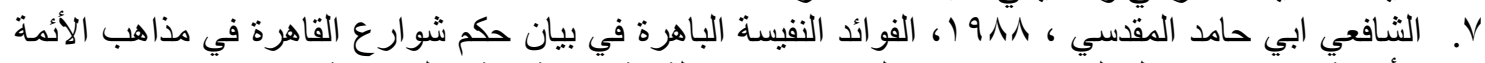

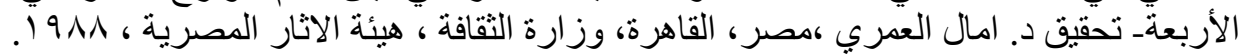

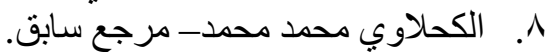

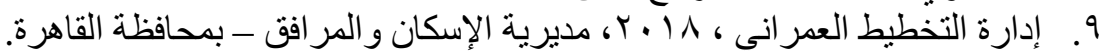

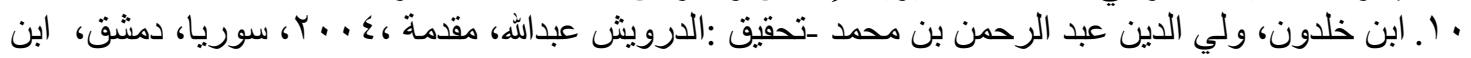

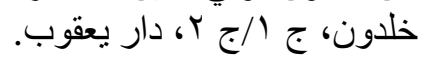

11. Moughtin,C ،1999, Urban Design - Streets \& Squares, Butterworth Ltd,UK. r ا. . بلدية دبي ،ع . . بوثيقة دبي للحفاظ و الصيانة علي المباني و المناطق التاريخية، الامارات العربية المتحدة، دبي. با. التوني سيد ، عبد القادر نسمات، و99 19 ، إشكالية النسيج و الطابع ، مصر ، القاهرة. 14. Lynch Kevin, 1960, the image of city - London the MIT press .

10 إلداية دبي - مرجع سابق.

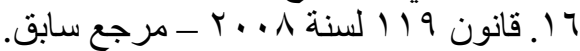

V ا. سرحان علاء، بو99 19، مظاهر الإدر الك الحسي بالفر اغات الحضرية ، رسالة دكتور اه غير منشورة، جامعة الإسكندرية.

18. Cooper,F., 1998، People Places - Design Guidelines for Urban open Space , University of California, Bekeley, NY.

19. احمد حسن محمود، 99191، إحياء المناطق التاريخية من خلال أعادة توظيفها - رسالة ماجستير ، مصر

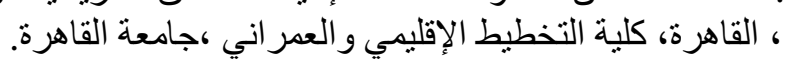

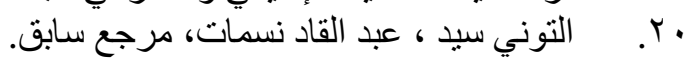

21. http://www.unesco.org/new/ar/cairo/culture/tangible-cultural-heritage/

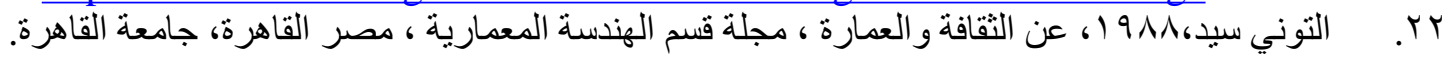

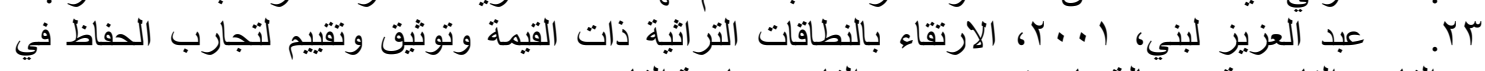

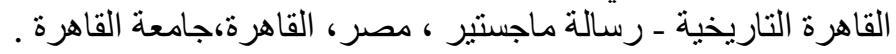

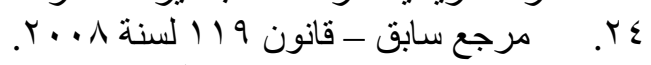

26. www.unesco.org

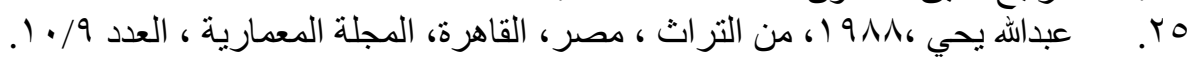

27. www.icomos.org

28. Venice charter, www.icomos.org/charters

29. http://whc.unesco.org/fr/conventiontext

30. Washington charter for historic cities, www.icomos.org/charters

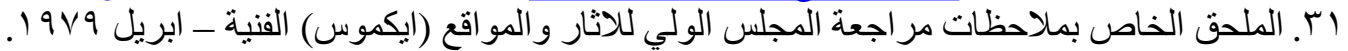

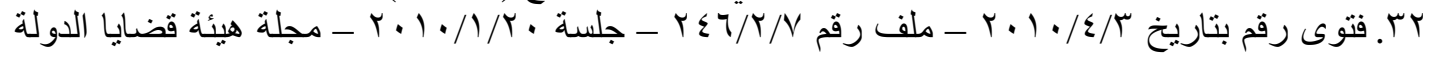

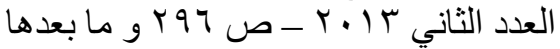

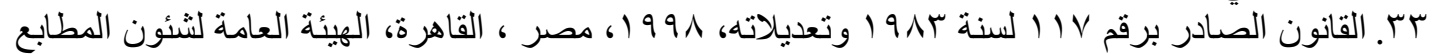

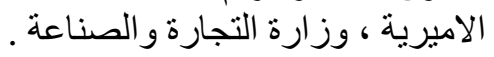

